\title{
REFLEXIONES EN TORNO AL USO DE EMBARCACIONES MONÓXILAS EN AMBIENTES BOSCOSOS LACUSTRES PRECORDILLERANOS ANDINOS, ZONA CENTRO-SUR DE CHILE
}

\author{
DIEGO CARABIAS A.", NICOLÁS LIRA S." Y LEONOR ADÁN A."
}

\begin{abstract}
RESUMEN
El presente trabajo propone una reflexión en torno a las prácticas de navegación interior en los ambientes boscosos de lagos subandinos del centro-sur de Chile. Se realiza una revisión crítica de los antecedentes disponibles para estas tecnologías de transporte, y en particular, de las canoas monóxilas indígenas, desde la arqueología, la etnohistoria y la etnografía. Se analizan las implicancias teóricas del uso de embarcaciones por parte de grupos Arcaicos y Alfareros continentales tomando como referencia antecedentes propuestos en estudios históricos y arqueológicos, y se discute sobre la importancia relativa y la profundidad temporal de estas prácticas en el área de los lagos araucanos.
\end{abstract}

PALABRAS CLAVES: Tecnología, embarcaciones, movilidad, rutas acuáticas, bosques templados.

\section{THOUGHTS ON THE USE OF LOGBOATS IN ANDEAN PRECORDILLERAN LAKE FOREST ENVIRONMENTS, CENTRAL-SOUTH CHILE}

\begin{abstract}
This paper proposes some thoughts on the use of watercraft on interior waters within the precordilleran lake forest environments of central-south Chile. A critical revision of available information related to water transport and indigenous logboats in particular is conducted from an archaeological, ethnohistorical and ethnographical perspective. Theoretical implications regarding watercraft use by continental Archaic and Ceramic period populations according to archaeological and historical proposals are analyzed, and the relative importance and antiquity of these practices in the Araucanian Lake District is discussed.
\end{abstract}

KEYWORDS: Technology, watercraft, movility, waterways, temperate forests.

* ARKA Consultores. Casilla 21, Correo Central, Valparaíso. Chile. dcarabias@arkachile.cl

* Université Paris 1 Panthéon-Sorbonne, UMR 8096, ARCHAM, 3 rue Michelet 75006 Paris, France.

Nicolas.Lira-San-Martin@malix.univ-paris1.fr

Dirección Museológica, Universidad Austral de Chile. Casilla 586, Isla Teja, Valdivia. Chile. ladan@uach.cl 


\section{INTRODUCCIÓN}

Diversos investigadores han destacado la importancia biogeográfica de los cursos de agua en la zona centro-sur de Chile como rutas naturales para los tránsitos regionales, vías articuladoras de la movilidad y la organización de los sistemas de asentamiento de los grupos humanos (Cfr. Aldunate 1989; Dillehay 1990; Adán y Mera 1997; García y Mera 2007).

En particular, José Bengoa (2003) ha planteado la tesis que los grupos mapuche y sus antepasados habrían establecido una sociedad ribereña en torno a los cursos y cuerpos de agua de la zona centrosur, haciendo uso intensivo de embarcaciones, para transformarse en tiempos históricos en una sociedad eminentemente ganadera. Esta propuesta, resulta estimulante e innovadora en el sentido de que cuestiona poderosamente los fundamentos de la etnología clásica de los grupos indígenas del extenso territorio mapuche-williche. Efectivamente, la mirada histórica, y en alguna medida, también la perspectiva arqueológica, han enfatizado el carácter agrícola, sedentario y ganadero del pueblo "araucano" (Cfr. Cooper 1946; Steward y Faron 1959). Esta mirada homogeneizadora y esencialista conlleva una evidente subvaloración de la amplia variabilidad de formas de adaptación y diversidad de recursos de los ambientes de la cordillera, valles y costa que justamente caracteriza tempranamente a los grupos Arcaicos, Alfareros y Mapuche históricos.

La escasa atención prestada a las prácticas de navegación interior o continental y al papel de los cursos y cuerpos de agua como vías de transporte, comunicación e intercambio resulta rotunda $e$ indiscutible. El desconocimiento del tema alcanza a tal grado que en la literatura se advierten problemas graves. Como la idea de que el transporte en embarcaciones en tiempos prehispánicos era poco relevante porque la mayoría de la población indígena habitaba en valles del interior donde existían escasos ríos navegables (Steward y Faron 1959: 277). O la noción de que las canoas monóxilas fueron un elemento cultural externo introducido en el período de contacto por los españoles en el centro de Chile (Edwards 1965: 54-58). Evidentemente, la valoración de los transportes prehistóricos se encuentra mediada por las expectativas culturales de las cualidades que debiera poseer una buena embarcación, y en ese sentido, los botes monóxilos con frecuencia han sido considerados funcional y tecnológicamente de segunda categoría (Nymoen 2008).

La idea de la cultura ribereña propuesta por Bengoa resulta sugerente y útil como motor de nuevas hipótesis de trabajo, pero se mantiene en el plano de formulaciones lógicas, pero sin mayor apoyo empírico. Desde la arqueología por otra parte, la estrecha relación de las comunidades humanas con los diversos ecosistemas boscosos regionales ha sido sistematizada en dos formulaciones de utilidad para la comprensión de las prácticas y técnicas de navegación en la zona centro-sur de Chile (Cfr. Lira 2007; 2010). Para la zona de Chiloé y el seno del Reloncaví, se ha propuesto el desarrollo de un temprano núcleo de adpatación marítima a partir del Holoceno Medio (Rivas et al. 1999; Rivas y Ocampo 2010). Los desarrollos particulares a este núcleo septentrional tendrían como antecedente una "tecnología de la madera" originada en los bosques del centro-sur y desplegada en un modelo de transición regional en ambientes de ecotono bosque-mar, relacionado directamente con la navegación y la formación de poblaciones canoeras (Ocampo y Rivas 2004: 319). En el sector de los lagos araucanos (Thomasson 1963), por otra parte, investigaciones efectuadas en torno al sistema lacustre del Calafquén han documentado una larga secuencia ocupacional con patrones tecnológicos y de uso de recursos con fuerte continuidad temporal. Entre éstos destacan una tecnología lítica expeditiva con escasas piezas formatizadas, a diferencia de lo que ocurre en otros ambientes regionales contemporáneamente, un aprovechamiento reiterado de mamíferos de pequeño y mediano tamaño propios de estos bosques, y una industria ósea singular y reiterada. Tales características, identificables en ocupaciones arcaicas, son integradas por poblaciones que incorporan las innovaciones alfareras tempranamente, participando de una Tradición Arqueológica de Bosques Templados, que evidencia una estrategia ocupacional en estrecha relación y conocimiento de los sistemas boscosos (Adán et al. 2004; Adán et al. 2005; Adán et al. 2010),

En los últimos años este equipo de trabajo ha desarrollado un enfoque interdisciplinario de investigación que, entre otras cosas, ha posibilitado la sistematización de los hallazgos aislados de canoas monóxilas en el centro-sur (Lira 2007, 2008-2009), el trabajo etnográfico y etnoarqueológico con las 
comunidades de estos territorios lacustres (Godoy 2009; Godoy y Lira 2007) y el estudio de estas evidencias en su contexto arqueológico a través de la incorporación de técnicas de arqueología subacuática (Carabias et al. 2005, 2007a, 2010).

En el presente trabajo se propone una sistematización y evaluación crítica de los antecedentes del uso de tecnologías de transporte acuático en el distrito de los lagos Araucanos a partir de tres líneas de evidencia independientes, la arqueología, la etnohistoria y la etnografía. El análisis se concentra específicamente en las canoas monóxilas, por representar el tipo de embarcación indígena más recurrente a nivel de hallazgos arqueológicos en el área de estudio. Una vez completada esa etapa se procede a discutir la profundidad temporal y a evaluar la importancia relativa que estas prácticas de navegación interior pudieron tener entre las poblaciones Arcaicas y Alfareras de los lagos Araucanos.

\section{MARCO BIOGEOGRÁFICO}

La sección cordillerana del territorio ubicado entre el río Bío-Bío y el seno de Reloncaví, en la zona centro-sur de Chile, se caracteriza, entre otros aspectos biogeográficos, por la presencia de un conjunto de lagos de origen glaciar (Mercer 1972) o lagos Araucanos (Thomasson 1963), volcanes, muchos de ellos activos y con un importante registro de actividad (Moreno 1990; Riffo 1984), distintas formaciones del bosque templado (Armesto et al. 1996) y pasos cordilleranos que permiten un importante contacto con la vertiente oriental andina.

En el sector piemontano y cordillerano andino, las potentes glaciaciones de fines del Pleistoceno produjeron un fuerte sobreexcavamiento, que posteriormente fue ocupado por aguas de fusión, las que se encontraron con un cordón morrénico que actuó como muro de represamiento, originando las cuencas lacustres de los lagos andinos de mayor extensión en Chile (Subiabre y Rojas 1994). Las cuencas se orientan de este a oeste y acumulan las aguas de sus afluentes, aumentando sus caudales en otoño e invierno debido a las precipitaciones estacionales (Soto y Campos 1996). Como ocurre con la mayor parte de los lagos del Sur de Chile, de origen glacial o tectónico glacial, ellos alcanzaron sus niveles y morfología actual entre 10.000 y 12.000 años AP (Mercer 1972).
Desde una perspectiva estructural y evolutiva, la sección cordillerana de la zona centro-sur puede ser entendida como glacio-volcánica. Desde fines del Pleistoceno prácticamente toda la cordillera estuvo cubierta por la grandes masas glaciares, las que primero modelaron el área formando los principales valles, lagos y lagunas andinas. Posteriormente, durante el Holoceno, sería la incesante actividad volcánica, presente hasta nuestros días, la que ha terminado por definir y modelar el ambiente (Riffo 1984; Gardeweg et al. 1990). Producto del factor volcánico, se debe entender esta región como "tremendamente dinámica", puesto que no es sólo la actividad eruptiva la que está constantemente modificando el paisaje, ya sea mediante la emisión de coladas que queman y abren sectores de bosque, cambiando y creando cursos de agua, la formación de lahares, o lluvias de ceniza que cubren grandes extensiones areales, sino también por la presencia de "volcanes dormidos", como aquéllos próximos a la costa sur del lago Caburgua, que actualmente corresponden a cerros de mediana altura totalmente cubiertos de vegetación y a los que "se les ha considerado de una edad que no va más allá de los 5 mil años, pues no muestran evidencias de erosión glacial" (Riffo 1984: 15).

La sistematización en secciones biogeográficas de la zona centro-sur propuesta por Aldunate (1989), fundamentalmente sobre la base de los recursos vegetacionales (Cfr. Gajardo 1994), reconoce un sector septentrional, el que sobre los $900 \mathrm{~m}$ presenta bosques de araucaria, destacables por sus frutos de alto valor alimenticio, un sector meridional, en cuya precordillera las araucarias son remplazadas por bosques de lenga, y un sector oriental que comprende a la precordillera y pampas argentinas del norte y centro de la Provincia del Neuquén (Aldunate 1989: 330-332).

En términos vegetacionales, el sector septentrional se caracteriza por el Bosque caducifolio alto-andino con araucaria: dado por la asociación de bosque de araucaria (Araucaria araucana) y lenga (Nothofagus pumilio), que se distribuye por las laderas altas y cumbres de los macizos cordilleranos, asociado a los sustratos de origen volcánico (Cfr. Donoso 1993: 84). El sector meridional, en cambio, estaría definido por la presencia del Bosque caducifolio mixto de la Cordillera de los Andes: dado por la asociación de bosque de raulí (Nothofagus 
alpina) y coihue (Nothofagus dombeyi) y del Bosque Laurifolio de los Lagos, el que se da especialmente asociado al ámbito de lagos de piedmont de origen glaciar y en donde domina el ulmo (Eucryphia cordifolia), la tepa (Laurelia philippiana) y tineo (Weinmannia trichosperma) (Armesto et al. 1996: 71, 76). Estas distinciones vegetacionales podrían tener un correlato faunístico, aunque hasta ahora sólo se conoce la situación en algunos transectos del bosque templado (Cfr. Murúa 1995).

En el sector septentrional, la Cordillera de Los Andes comienza a descender notablemente en altura, exhibiendo pasos por bajo los $1.000 \mathrm{msnm}$, los que pueden ser utilizados durante todo año. En el sector meridional la cordillera se presenta aún más baja que en el sector anterior, ofreciendo innumerables pasos hacia el oriente que pueden ser empleados incluso durante el invierno, algunos con alturas inferiores a los 700 msnm (Aldunate 1989: 331 - 332).

\section{EVIDENCIAS ETNOHISTÓRICAS Y ETNOGRÁFICAS DE CANOAS MONÓXILAS EN LA ZONA CENTRO-SUR}

Las fuentes documentales del período de contacto ofrecen abundantes referencias a los tipos de embarcaciones y prácticas de navegación indígenas en el Centro - Sur de Chile. Aunque se da cuenta de una importante variabilidad de tipos y materiales (Cfr. Edwards 1965; Lothrop 1932), uno de los principales son las canoas monóxilas. $\mathrm{Al}$ respecto, las obras de los cronistas del siglo XVI (Góngora Marmolejo 1862; Mariño de Lobera 1865; Vivar 1966) e historiadores del siglo XVII (Diego de Rosales 1877-1878) destacan principalmente las aplicaciones estratégico - militares de estos medios de transporte en los conflictos hispano-indígenas. Con posterioridad, particularmente durante el siglo XIX, los viajes científicos, hidrográficos, de exploración y comercio registrarán la persistencia temporal de estas tecnologías en períodos republicanos ( $C \mathrm{fr}$. Fonck 1900; Juliet 1874; Philippi 1865; Treutler 1861, 1958; Vidal Gormaz 1867, 1879).

En los lagos Araucanos, específicamente, existían diversos tipos de embarcaciones indígenas en funcionamiento. En el siglo XVI, el lago Villarrica era navegado por canoas (Vivar 1966: 157). En el siglo XVII, los serranos indios pewenches de la Villarrica navegaban las aguas del lago Epulafquén, en el actual territorio de la Provincia de Neuquén, Argentina, en balsas y canoas; mientras que los grupos pewenches que habitaban más al sur, junto al lago Nahuelhuapi, actual Provincia de Río Negro, y otros cuerpos de agua cordilleranos inmediatos a Chiloé utilizaban dalcas o piraguas (Diego de Rosales 1877-1878, Vol. I: 176). En lago Ranco se empleaban canoas en el siglo XVI (Mariño de Lobera 1865: 402) y XVII (Diego de Rosales 1877-1878, Vol. I: 255). Para el cruce del lago Llanquihue los españoles utilizaban canoas en el siglo XVI (Góngora Marmolejo 1862: 30), pero ya durante el XVII era navegado en piraguas tanto por los españoles como por los indios de Pura-aylla en sus incursiones militares (Góngora Marmolejo 1862: 30).

La tradición oral también puede ser considerada una importante línea de evidencia independiente para la investigación arqueológica de embarcaciones prehistóricas (Deweese 2007). Aunque las canoas monóxilas de la zona Centro- Sur en gran medida han desparecido, aún son utilizadas por grupos mapuche lafkenches en la zona costera del lago Budi, en la Araucanía, y en el extremo sur de la Isla Grande de Chiloé, por comunidades mapuche williches en el estuario del río Yaldad. En la zona precordillerana de los lagos Calafquén, Villarrica y Caburga recientes investigaciones etnográficas y etnoarqueológicas entre poblaciones pewenches han permitido la recuperación de valiosa información sobre las prácticas de fabricación y utilización de canoas, wampos o "canogas" como aquí son denominadas. A partir de la tradición oral diversos aspectos como la selección de maderas, herramientas y técnicas para la fabricación de las canoas, circuitos de navegación, localización de puertos, organización colectiva y sistemas de comunicación han sido documentados (Godoy 2005, 2009; Godoy y Lira 2007).

La persistencia temporal en el uso de estos medios tradicionales parece variar sustancialmente de una cuenca lacustre a otra; mientras en el lago Calafquén la memoria oral mantiene vigente información sobre el uso de estos transportes, en el lago Villarrica prácticamente ha sido imposible reportar datos etnográficos. En el Calafquén las fuentes orales coinciden en que las canoas monóxilas se mantuvieron en uso hasta mediados de siglo XX cuando fueron remplazadas por botes de madera de diseño europeo (Godoy 2005). Aunque los testimonios atribuyen el reemplazo al arribo de aserraderos en coincidencia 
con la situación que explicaría la desaparición de estas embarcaciones entre 1880 y 1900 en el lago Nahuelhuapi (Fernández 1978: 49), lo más probable es que otros factores deban ser considerados. En el lago Villarrica el primer servicio regular de navegación a vapor se estableció hacia 1886 para conectar los asentamientos militares de Villarrica y Pucón. En Panguipulli, inmediatamente al sur, la prohibición de navegación en canoas y la destrucción sistemática de las embarcaciones indígenas fue impuesta en 1904 por la primera compañía maderera que estableció un circuito de navegación a vapor entre Panguipulli y Chosuenco (Díaz Meza 1907). Eventos similares de destrucción masiva de canoas indígenas se habrían registrado en el lago Ranco en la década de 1930 al ponerse en servicio sistemas de navegación de vapores (Bengoa 2003: 75).

Las fuentes orales del Calafquén destacan la importancia de las canoas en tiempos históricos tardíos - cuando aún no existían caminos de circunvalación terrestre- como sistemas de comunicación y transporte entre localidades ribereñas del lago como Pucura, Tralahuapi y Coñaripe, el traslado de personas y bienes como parte de un sistema tradicional de visitas periódicas entre parientes e intercambios materiales (Godoy 2005), en forma coincidente con lo propuesto por Bengoa (2003:79 - 86).

Más aun, los testimonios etnográficos aportan datos específicos sobre sistemas de comunicación a larga distancia mediante señales visuales y sonoras entre comunidades ribereñas de la misma cuenca lacustre para enfrentar en forma organizada situaciones de emergencia. Mediante señales de humo con fogatas en lugares predefinidos e instrumentos sonoros como el küll-küll (corneta fabricada de cuerno de vacuno) se solicitaba de una localidad a otra el envío de canoas que estaban a cargo de personas específicas dentro de la comunidad (Godoy 2009: 15 - 16). En el sector de Putue, en el curso alto del río Toltén, identificado como un lugar tradicional de cruce mediante canoas la comunidad también destaca el uso de este instrumento para solicitar apoyo militar entre ambas riberas (Bustamante et al. 2005). Resulta relevante notar que esta información oral actual es notablemente consistente con la aportada por fuentes etnohistóricas que describen enfrentamientos hispano-indígenas para la zona costeña del lago Budi en el siglo XVI, donde se describe el uso de señales de humo y cornetas para la convocatoria de canoas (Rosales 1877-1878, Vol. II: 22 -23).

Lo anteriormente expuesto refuerza la tesis de que estos mecanismos forman parte integral de los sistemas de adaptación cultural de estas poblaciones, en forma transversal desde los ambientes lacustres costeros a los cordilleranos del Centro - Sur de Chile y probablemente más allá de Los Andes, hacia el territorio lacustre de Patagonia Septentrional en Argentina.

\section{Fabricación}

Existe escasa información etnohistórica disponible sobre los procesos de construcción de las canoas monóxilas del Centro - Sur. Probablemente la descripción más detallada la ofrezca el jesuita Diego de Rosales en 1678:

La otra embarcacion muy usada en este reyno es de canoas: derriban un arbol gruesso y alto, desvastan el tronco o plan que ha de servir de quilla, caban el corazon hasta dexar el plan de cuatro dedos de grueso y los costados poco mas de dos, y acomodan el güeco para buque, la extremidad mas delgada para proa, y la mas gruesa para popa [...] (Rosales 1877, Vol. I: 173-14)

Los datos aportados por el autor de la Historia del Reino de Chile, Flandes Indiano apuntan a un trabajo de la madera realizado con instrumentos básicos y técnicas de aplicación del fuego, un proceso lento y trabajoso, que, no obstante, permitía resultados satisfactorios:

No son en Chile los arboles tan gruesos, ni tienen los indios instrumentos con que labrar los palos que no alcanzan, sino un toqui o una azuelilla del tamaño de un formon que la encaban como martillo, y con su flema van cabando un arbol gruesso, gastando mucha chicha en tres tiempos, uno al cortar el arbol, otro al desvástarle y otro al concabarle, y otro gasto y fiesta al echarla al agua. $Y$ antes que tuviesen instrumentos de ierro, y los que oy no los tienen en las provincias cercanas al Estrecho de Magallanes, hazenlas canoas con gran trabaxo y caban un arbol muy gruesso con fuego, y con unas conchas del mar le van raiendo, aplicando el fuego moderadamente al rededor del arbol, atendiendo a que no gaste sino aquella parte necesaria para derribarle, y con lentas llamas le trozan, sucediendo las conchas, que ni tienen 
mas achas ni azuelas para descortezarle, pulirle $y$ darle la perfeccion. Y con el mismo trabaxo y faltas de herramientas abren el buque, quemando a pausas el corazon del arbol y raspando con las conchas lo que labra el fuego; y aunque tarde $y$ espaciosamente, vienen a sacar su embarcacion tan bien labrada como si tubieran los instrumentos necesarios; y hazen mas que nuestros artifices, pues sin instrumentos obran a fuerza de industria y de paciencia lo que ellos con ayuda de azerados instrumentos. (Rosales 1877-78, Vol. I: 174).

Rosales identifica las herramientas de trabajo con un toki o una azuela pequeña del tamaño de un formón enmangada como martillo. En el Chiloé de la segunda mitad del siglo XVIII, el hacha de piedra utilizada para fabricar embarcaciones se denominaba cachalcura (Güell 1982: 235). En la zona del Calafquén, las fuentes etnográficas actuales señalan que entre las herramientas utilizadas para excavar troncos -hacha, azuela, gubia, cuñas- también figura una azuela de mano denominada maichiwe (Godoy 2005; Godoy y Lira 2007).

A pesar del reemplazo del instrumental lítico por herramientas de hierro en períodos de postcontacto, el proceso de fabricación de estos medios de transporte aparentemente continuó manteniendo un carácter marcadamente conservador, sin mayores innovaciones tecnológicas. Ya en la segunda mitad del siglo XIX, en sus viajes de exploración de los lagos Lacar y Nahuelhuapi, Cox señala que en el Sur de Chile los pobres fabrican sus canoas ahuecando troncos de coihue, simplemente con fuego $y$ herramientas muy imperfectas (Cox 1863: 32). En su exploración del río Bueno y lago Ranco en 1877 , Señoret recalca que las canoas empleadas por los indígenas son de una sola pieza y toscamente labradas (Señoret 1878: 36).

La referencia anterior de Rosales al considerable gasto de chicha y fiesta que se realizaba durante las fases de construcción, al talar el árbol, desbastar y ahuecar el tronco, y, finalmente, lanzar la canoa al agua, resulta especialmente trascendente porque pone de manifiesto que la fabricación, así como la utilización, de las embarcaciones es una actividad eminentemente colectiva y socialmente relevante. Etnográficamente se halla documentado que desde las primeras etapas del proceso de construcción de las embarcaciones monóxilas, que involucran la selección y talado del árbol en el bosque, existen acciones rituales, mágicas y simbólicas asociadas (Arnold 1995; Guerrero 2006).

\section{Funciones}

Las canoas monóxilas eran utilizadas principalmente para el cruce o vadeo de ríos y lagos, y el transporte de personas y productos en general a lo largo de los extensos sistemas de comunicación que conforman las principales hoyas hídricas de la zona Centro - Sur. Con anterioridad a 1584, Góngora Marmolejo describía las canoas indígenas de la zona del Bío - Bío como unos maderos grandes cavados por de dentro a manera de artesa, y en aquel hueco que en si tienen pasan los rios por grandes que sean (Góngora Marmolejo 1862: 50).

Evidentemente, las canoas cumplían una importante función para las actividades de pesca, caza y recolección en diferentes ambientes, fluviales, lacustres y marinos. En el siglo XVII, los indios de la Imperial las utilizaban para la abundante pesca de la corvina, especie que se captura por lo regular en zona de rompientes (Rosales 1877-78, Vol. I: 174). En la costa del río Bueno, estas embarcaciones eran empleadas para acceder desde el interior por el río al mar y realizar actividades pedestres de recolección de algas y mariscos en la playa (Phillipi 1865: 37). Las canoas excavadas en un solo tronco se utilizaban para la pesca y calado de redes en el río Mehuín (Vidal Gormaz 1879: 167, 172). También se empleaban para la recolección de huevos de pájaros durante el verano en las islas de lagos precordilleranos como el Calafquén (Treutler 1861: 141).

Particular importancia parecen haber desempeñado las canoas para el traslado de productos para su intercambio. Desde el momento de contacto, las crónicas destacan el intenso movimiento de embarcaciones a lo largo del complejo sistema fluvial del estuario del río Valdivia:

Es tambien de grande recreacion el ver muchos brazos de rios que vienen corriendo de diversas partes y llegan a la ciudad: que aunque son pequeños todavía andan a placer las canoas por ellos, lo cual es la causa de que esté la ciudad mui bien servida, y proveida, porque en las canoas traen los indios todo lo necesario, como es yerba, leña, y muchos mantenimientos; y no menos deleite en ver entrar tantas canoas por aquellos rios hasta llegar a las casas (Mariño de Lobera 1865: 139). 
Este sistema de intercambio a larga distancia por navegación fluvial se mantendrá en el tiempo. En 1643 los buques de la expedición holandesa de Brouwer intercambian ganado, chicha y otros productos con los habitantes de Valdivia, quienes se acercaban en grupos de cerca de treinta embarcaciones (Medina 1928: 110, 113). Los mismos holandeses nos legan una hermosa planta de la ciudad de Valdivia donde grafican las embarcaciones indígenas cursando el río, también ocupado por embarcaciones mayores de los europeos (Guarda 1994: 20-21). Hacia 1678 cada semana entraban por el rio cien canoas cargadas de pescado, frutos de la tierra y legumbres (Rosales, 1877-78, Vol. II: 464). A fines del siglo XVIII, tanto indios como españoles se comunicaban regularmente con Valdivia mediante canoas procedentes de diez leguas ( 55 km) y más de distancia (González de Agüeros 1791: 31). A mediados del siglo XIX, todavía una inmensa cantidad de botes y canoas subían y bajaban por el río, transportando los productos que los pobladores de las cercanías llevaban a la ciudad y al puerto de Corral; aprovechando la temporada favorable grupos de indígenas se congregaban en el embarcadero para intercambiar vacunos y caballos por otros productos (Treutler 1958: 346).

Las canoas monóxilas también cumplieron una destacada función en aplicaciones estratégico - militares y de exploración, principalmente durante el período de las guerras de Conquista. Las fuentes tempranas revelan que son empleadas en forma organizada y eficiente por los grupos indígenas para evitar y repeler los avances hispanos, realizar aprovisionamientos logísticos de alimentos y llevar adelante acciones ofensivas. Son incorporadas tempranamente por los propios españoles quienes las emplean para el primer reconocimiento del puerto de Valdivia, Corral y las exploraciones del lago Llanquihue (Góngora Marmolejo 1862: 30; Vivar 1966: 158). En los primeros años de la Conquista se describen importantes enfrentamientos navales y terrestres hispano-indígenas en el lago Budi (Vivar 1966: 185 - 188). Para el alzamiento de 1580, los indios rebelados a las orillas del lago Ranco recibían suministros a través del río que conectaba con el valle de Maque (Maihue) (Mariño de Lobera 1865: 344), probablemente el río Calcurrupe, que en un recorrido de $16 \mathrm{~km}$ conecta los lagos Maihue y Ranco. Grandes canoas con mujeres y hombres a bordo servían para aprovisionar de alimentos a los fuertes indígenas rebelados en el lago Ranco y la captura de 15 de ellas era estimada de gran importancia por Pedro de Valdivia por ser considerados los instrumentos que eran sus piés y manos (Mariño de Lobera 1865: 402).

Para el siglo XVII se describe un gran enfrentamiento naval en las aguas del lago Epulafquén, en la vertiente oriental, entre canoas indígenas y balsas construidas por los españoles, como parte del malón de Challupén liderado por Luis Ponce de León (Rosales 1877-78, Vol. III: 394 - 397). En el mismo período se utilizaban piraguas por parte de los españoles e indios amigos de Chiloé para maloquear a los indios rebelados del lago Nahuelhuapi (Rosales 1877-78, Vol. I: 257).

Las canoas monóxilas estaban bien adaptadas para las condiciones de navegación en los ríos y lagos de la zona Centro - Sur de Chile. Navegar en ríos veloces y caudalosos implica choques inevitables con obstáculos como troncos sumergidos y rocas, por lo que estas embarcaciones se caracterizaban por cascos sólidos, robustos y resistentes. Esto mismo las hacía pesadas y poco apropiadas para técnicas de "porteo" o arrastre entre cuerpos y cursos de agua. En 1554 Pedro de Villagrán tardó dos días en llevar canoas por un tramo de media legua ( 2,75 km) entre el mar y el río que desaguaba el lago Budi a causa de las llevar arrastrando y haber poca gente que las llevase (Vivar 1966: 186). De todos modos, en el siglo XIX los "bongos" aún eran considerados los mejores medios para la exploración de los grandes sistemas hídricos como el río Maullín porque aunque eran pesados de impulsar, también retrocedían por la corriente con lentitud (Juliet 1874: 249). Entre las principales desventajas se señala que eran inestables (Güell 1982: 233; Rosales 1877-78, Vol. I: 174), aunque fuentes etnográficas especifican que su condición de inestabilidad era sólo mientras se hallaban detenidas y se ganaba equilibrio en movimiento (Godoy 2005).

Las fuentes etnohistóricas permiten identificar algunas técnicas de navegación particulares al área de estudio que pueden identificarse como rasgos culturales. Quizás la principal sea la práctica de "singar", remar impulsando y gobernando la embarcación sentado a popa. Según Rosales, el que gobierna con una pala que llaman canalete, y quando es grande sirven otros dos de remeros a 


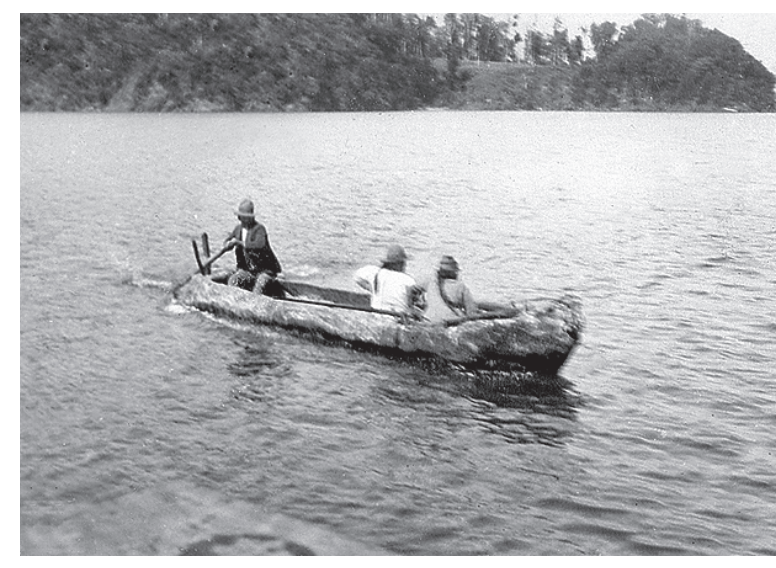

Fig. 1. Canoa monóxila en uso durante la segunda mitad del siglo XIX.

[Fuente: Valck, 1870. Colección particular Álvaro Beza]

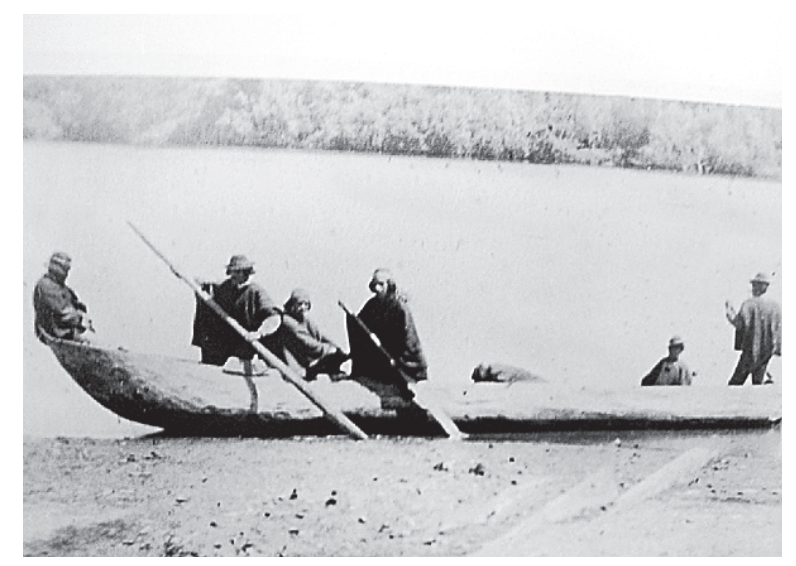

Fig.2. Canoa monóxila navegando en el lago Ranco durante la primera mitad del siglo XX.

[Fuente: Archivo Fotográfico Dirección

Museológica Universidad Austral de Chile] los lados y reman en pié sin estribar en el bordo de la canoa, con que la trahen tan ligera que apenas toca el agua (Rosales 1877-78, Vol. I: 174). En Chiloé, los remos de estas canoas son cortos, que más parecen palas que remos (Güell 1982: 233). En una imagen tomada por el fotógrafo E. Valck de Valdivia hacia 1870 se advierte una canoa monóxila orillada con seis tripulantes, con dos remeros hacia proa y uno a popa, de pie y con remos de diferente longitud (Lira 2008-2009: 117 - Fig. 5). Aparte del Sur de Chile, la técnica indígena de bogar de pie sólo estaría documentada en las costas del Pacífico de Sudamérica para Perú, aunque en la costa atlántica resultaba frecuente en el litoral de Brasil y Uruguay y en el río Paraná; los grupos indígenas del interior de Sudamérica aunque impulsan de pie sus embarcaciones con pértigas mayoritariamente reman en posición sentada (Lothrop 1932: 232).

En la primera fotografía de una secuencia captada por R. Knitell en Puerto Nuevo en el lago Ranco hacia 1934 - 1936, es posible observar una canoa monóxila navegando con tres ocupantes, un hombre sentado a popa sobre la regala y dos mujeres en su interior de la banda opuesta, encuclillas hacia proa, lo que asegura una distribución equilibrada del peso (Lira 2008-2009: 113 - Fig. 1). El hombre, quien sirga la embarcación, fija el remo armado en un retén o pieza de madera en forma de horquilla que se fija al espejo o mamparo posterior de la canoa. En cada regala es posible advertir una horquilla de madera desempeñando la función de chumacera para el remo (Lira 2008-2009: 115 Fig. 3). Esto resulta relevante porque demuestra la incorporación de una modalidad de boga europea en tiempos históricos tardíos, sin prescindir de técnicas indígenas tradicionales para impulsar las embarcaciones monóxilas.

La navegación río arriba o contra la corriente podía ser efectuada siguiendo los tramos donde la velocidad del agua es menos intensa, con frecuencia a lo largo de las orillas. En casos de ríos correntosos, los indígenas de Osorno empleaban para remontarlos herramientas especiales de madera de luma endurecidas al fuego denominadas "choques" y "horquetas", que servían para tomarse de las ramas de los árboles de las riberas. Esta operación, aunque aparentemente sencilla, resultaba extremadamente riesgosa y denotaba el manejo de técnicas de navegación especializadas (Bengoa 2003: 76). En tiempos poshispánicos resulta frecuente la técnica de "sirgar" o llevar a la sirga una embarcación, es decir, remolcar desde tierra tirando mediante personas y/o caballos (Fernández 1997: 53-54).

En las fuentes documentales no se menciona el empleo de propulsión a velas para las canoas monóxilas, aspecto que contrasta con su empleo esporádico en las canoas de tablones o dalcas, aunque ésta tampoco parece haber tenido un origen prehispánico. Aunque Braicovich (2004: 97-98) consigna el uso de vela y balancines estabilizadores en una canoa monóxila por parte de una familia mapuche tardíamente en el lago Lacar en 1910, 
estos elementos probablemente han sido incorporaciones occidentales.

Probablemente uno de los principales riesgos para la navegación interior son las fuertes condiciones de oleaje que se pueden generar por efecto del viento en las extensas superficies de los lagos costeños y cordilleranos (Cfr. Mariño de Lobera 1865: 403; Rosales 1877-78, Vol. I: 254; Vivar 1966: 187). Particularmente violento resulta el "puelche" o "puihua", viento cálido y seco procedente de la cordillera que sopla en forma excepcional y suele perdurar varios días. La ola corta rizada que se forma en los lagos por el menor peso específico resultaba extremadamente peligrosa para las embarcaciones menores y el "puihua" era temido por los indígenas del lago Ranco (Señoret 1878: 37). Si se levantaba repentinamente un "puelche" se buscaba refugio en la playa más cercana. Treutler señala que en el lago Calafquén los indígenas hacían "pagos" con aguardiente y harina, ofrendas para agradecer el arribo a salvo tras un violento "puelche" (Treutler 1861: 145).

\section{Capacidades}

A partir de las evidencias etnohistóricas, es posible realizar una cálculo estimado de las capacidad de carga de las canoas indígenas. Las fuentes documentales indican que existía una variedad relativamente amplia de tamaño, lo que probablemente se relacionaba con aspectos como el ambiente geográfico, funcionalidad, disponibilidad de materiales, entre otros factores.

Las canoas empleadas por los españoles en 1581 para combatir a los indios rebeldes del lago Ranco permitían embarcar más de seis hombres (Mariño de Lobera 1865: 403) y las utilizadas para reducir a los indígenas del lago Budi, ocho hombres, incluyendo a cuatro indios remeros (Rosales 187778, Vol. II: 22). Rosales señala que son moderadas y distintas de las de Brasil y Colombia, que pueden transportar a 200 hombres, siendo la de mayor envergadura una observada en el río Toltén con capacidad para 30 personas (Rosales 1877-78, Vol. I: 174). Treutler afirma que las canoas monóxilas de la zona del Calle - Calle tenían con frecuencia capacidad para 100 quintales ( $4600 \mathrm{~kg})$ y espacio para 12 o más personas, pero que igualmente existían muchas de menor tamaño apropiadas para sólo un ocupante (Treutler 1958: 305). Señoret destaca que en las aguas del lago Ranco existían de inmensas proporciones, observando una donde cabían con comodidad tres o cuatro animales vacunos y seis a ocho personas (Señoret 1878: 36). Para el traslado de cargas pesadas o elementos voluminosos se podía aumentar la flotabilidad y la superficie, uniendo paralelamente dos o más canoas entre sí en forma de catamarán (Fonck 1900, Vol. II: 17).

En síntesis, el registro escrito permite concluir que las canoas monóxilas representaban medios de transporte que podían transportar pesos considerables, aunque significativamente menores que otras embarcaciones indígenas como las dalcas de Chiloé. Los datos etnohistóricos describen con regularidad el traslado de cargamentos y personas estimados entre aproximadamente 500 ó 750 kg y más de dos toneladas, pudiendo alcanzar excepcionalmente pesos de hasta cuatro y media toneladas.

\section{EVIDENCIAS ARQUEOLÓGICAS DE NAVEGACIÓN INTERIOR EN LA ZONA CENTRO-SUR}

El estudio de las evidencias directas de navegación prehistórica -los restos materiales de las embarcaciones- se encuentra fuertemente complejizado por la conservación en el tiempo de materiales orgánicos que no resultan frecuentes en el registro arqueológico. No obstante, en los últimos años, el descenso del nivel los cursos de agua localizados entre la costa y la cordillera en la zona Centro - Sur de Chile, por efecto de una disminución en las precipitaciones ha dado origen al hallazgo fortuito de varios restos de embarcaciones de tradición prehispánica. En 1996 en el lago Lanalhue, Región del Bío-Bío, se recuperaron los restos de una embarcación monóxila, los que, no obstante ser extraídos sin mediar una metodología científica fueron posteriormente objeto de un tratamiento de conservación con polietilenglicol (PEG) con la asesoría del Centro Nacional de Conservación y Restauración (CNCR) (Bahamondez y Valenzuela 2001); actualmente se encuentran en el Museo Mapuche de Cañete. En el verano de 1999, los restos de otra canoa monóxila habrían sido descubiertos y extraídos por buzos desde otro lago costero un poco más al sur, el lago Lleulleu, y donados al Museo Stom de Chiguayante. Otro hallazgo de embarcaciones monóxilas se habrían 


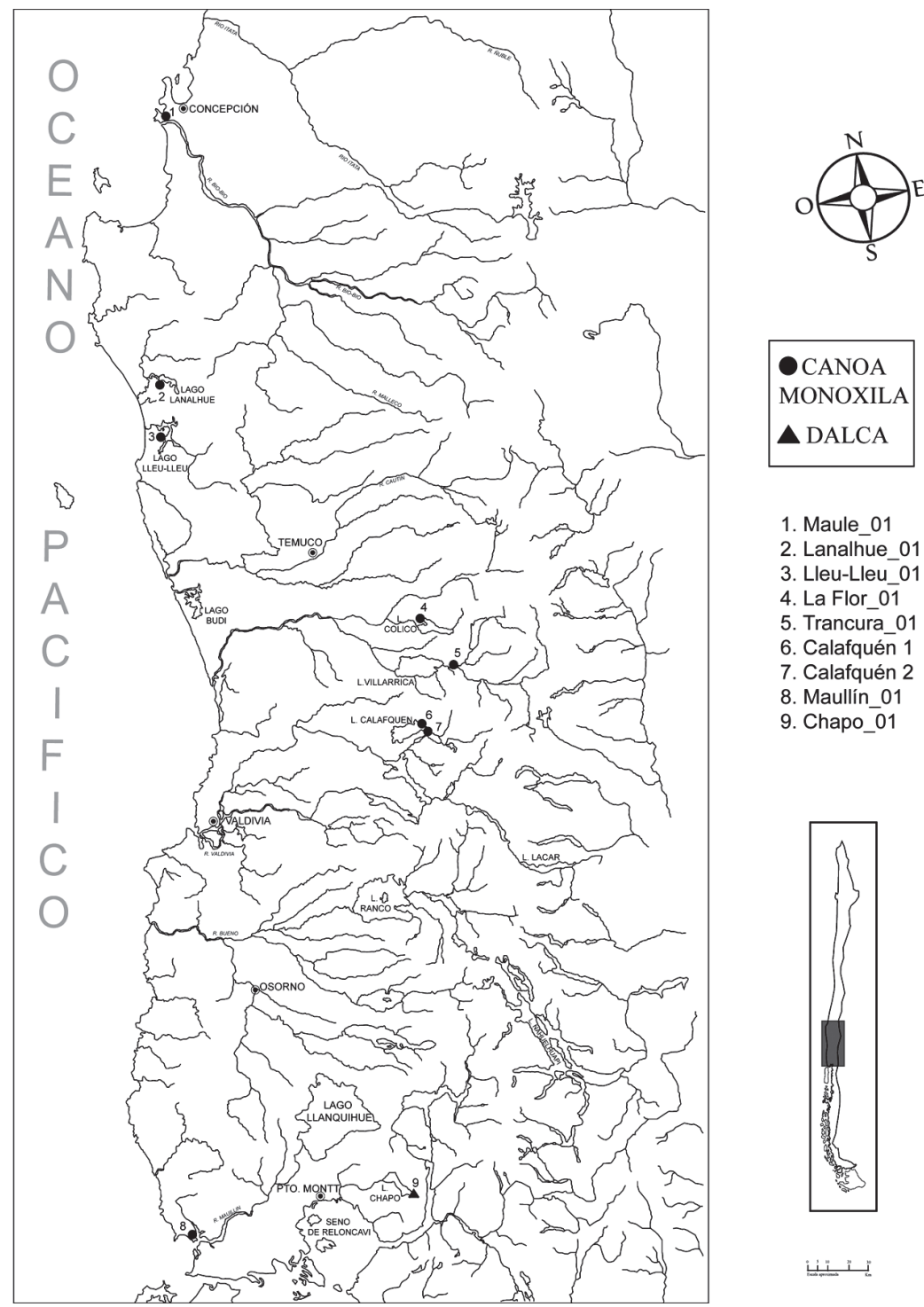

Fig. 3. Área de estudio y representación de los hallazgos de embarcaciones de tradición indígena registradas en la zona Centro - Sur.

registrado en 2004 en las riberas del río Maullín, desde donde también se rescató una monóxila. Además, con anterioridad se conocía la existencia de una pieza de este tipo en el Museo Regional de la Araucanía en Temuco, aparentemente procedente de la laguna La Flor, próxima al lago Caburga, la que por años constituyó un atractivo fundamental de la muestra. En el verano de 2005, buceadores recuperaron otra canoa de las aguas del río Trancura, en las cercanías de Pucón. Aparte de estos y otros hallazgos de embarcaciones monóxilas, en 1996 un fuerte descenso en el nivel de las aguas del lago Chapo dejó al descubierto los fragmentos de una dalca o canoa de tablones cosidos, los que fueron recuperados y actualmente se conservan en el Museo Juan Pablo II de Puerto Montt, siendo analizados arqueológicamente por nuestro equipo y fechados mediante ${ }^{14} \mathrm{C}$ convencional en $460 \pm 70 \mathrm{AP}$ (Beta 207295) (Carabias et al. 2007b)

En el marco de un proyecto anterior (FONDECYT 1040326), uno de nosotros realizó un trabajo de sistematización, documentación y 


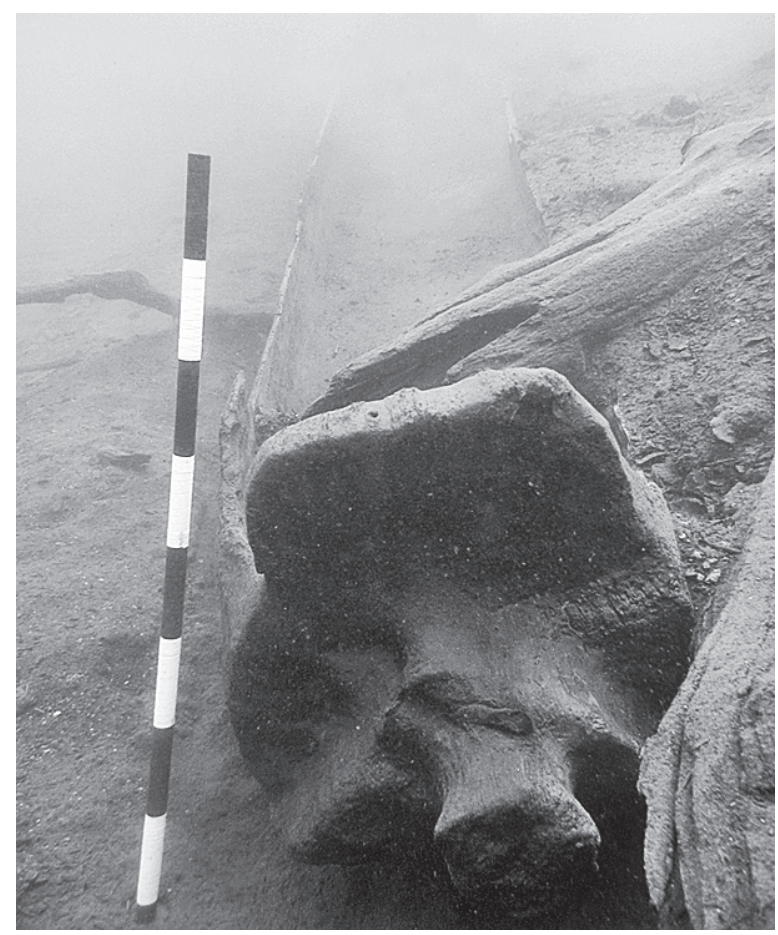

Fig. 4. Trabajos arqueológicos subacuáticos de documentación de la Canoa $N^{\circ} 1$ del sitio "Dos Canoas", en la localidad de Pucura, lago Calafquén.

análisis de seis canoas monóxilas correspondientes a hallazgos aislados, descontextualizados y depositados en museos públicos y privados del área. Además de la documentación de los atributos morfológicos e identificación taxonómica se obtuvieron fechados radiocarbónicos para tres de ellas (Lira 2007).

En el marco del mismo proyecto mediante la aplicación de técnicas de arqueología subacuáti- ca se realizó la intervención de un sitio localizado fortuitamente por buzos deportivos en el sector de Pucura, Lago Calafquén a aproximadamente $20 \mathrm{~m}$ de profundidad. El trabajo consistió en la documentación, y sondeos arqueológicos, análisis dendrológico, taxonómico y fechado radiocarbónico de dos canoas monóxilas en lo que se denominó sitio "Dos Canoas" del lago Calafquén (Carabias et al. 2005, 2007a). Los fechados directos sobre muestras de madera procedentes de la Canoa № 1 (Beta 205208) y de la Canoa № 2 (Beta 205209), arrojaron como resultado un fechado ${ }^{14} \mathrm{C}$ convencional de $130 \pm 70$ AP y 330 $\pm 80 \mathrm{AP}$, respectivamente. La investigación reveló que, aunque fabricadas con técnicas similares, ambas embarcaciones exhibían diferencias morfológicas sensibles en términos diseño del casco. No obstante su distancia cronológica, la selección del laurel o triwe (Laurelia sempervirens), una madera blanda y quebradiza, pero resistente a la humedad y fácilmente trabajable en comparación a otras especies más duras y resistentes del bosque templado, destaca como una patrón persistente en el tiempo.

Nuevas investigaciones sobre este yacimiento han permitido establecer un monitoreo en el tiempo y probar métodos de protección in situ de sitios sumergidos (Carabias et al. 2010), verificándose además la asociación de material cerámico con la Canoa N² (Carabias et al. 2010), aspectos que se pretende profundizar en el futuro.

La información general sobre las dimensiones máximas, madera utilizada y fechado radiocarbónico, de ocho ejemplares de embarcaciones monóxilas de la zona centro-sur se presenta a continuación en la Tabla 1.

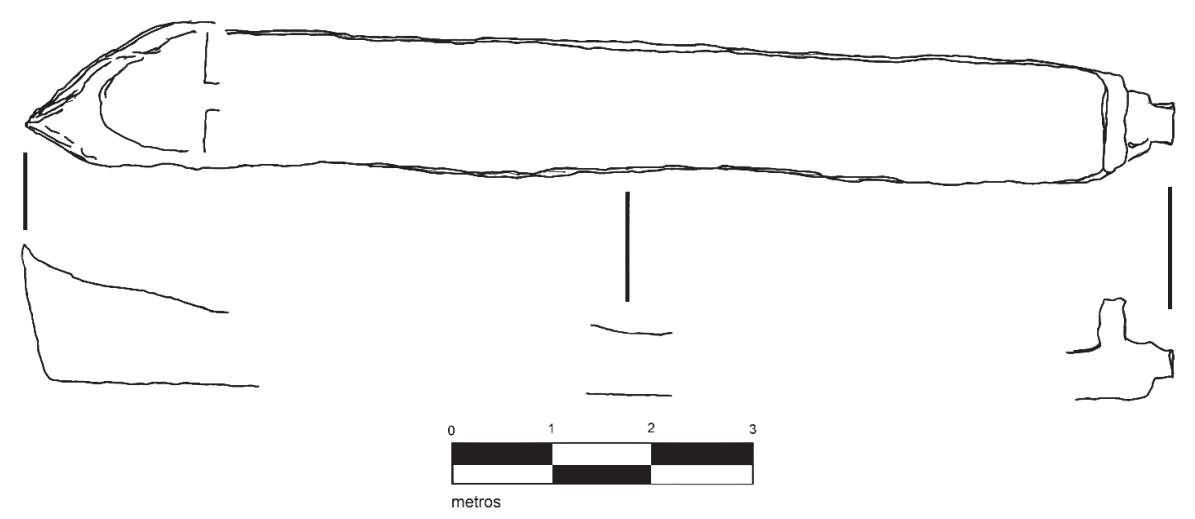

Fig. 5. Dibujo de planta y elevación de la Canoa № 2 del sitio "Dos Canoas", Pucura, lago Calafquén. 
Tabla 1. Embarcaciones monóxilas en el área de estudio.

[Fuente: Carabias et al. 2007; Lira 2007]

\begin{tabular}{|c|c|c|c|c|c|c|c|}
\hline Canoa & $\begin{array}{l}\text { Beta } \\
\text { № }\end{array}$ & $\begin{array}{l}\text { Fechado } \\
\text { Conv. } \\
\text { A.P. }\end{array}$ & $\begin{array}{l}\text { Cal. } 2 \text { Sigmas } \\
\text { (95\% probabilidad) }\end{array}$ & Taxón Madera & $\begin{array}{l}\text { Edad } \\
\text { mínima } \\
\text { (años) }\end{array}$ & $\begin{array}{l}\text { Longitud } \\
\text { (m) }\end{array}$ & $\begin{array}{l}\text { Ancho } \\
(\mathrm{m})\end{array}$ \\
\hline Maullín 01 & 220271 & $280+/-40$ & Cal. 1.500 a 1670 DC & Eucyphia cordifolia Cav & - & 7,34 & 0,99 \\
\hline Trancura 01 & - & - & - & $\begin{array}{l}\text { Nothofagus alpina } \\
\text { (P. et E.) Oerst }\end{array}$ & - & 5,72 & 0,85 \\
\hline Laguna La Flor 01 & 220272 & $270+/-50$ & $\begin{array}{l}\text { Cal. } 1.490 \text { a } 1.680 \text { DC } \\
\text { Cal. } 1.770 \text { a } 1.880 \text { DC } \\
\text { Cal. } 1.940 \text { a } 1.950 \text { DC }\end{array}$ & $\begin{array}{l}\text { Laurelia sempervirens } \\
\text { (R. et P.) Tul }\end{array}$ & - & 5,96 & 1,04 \\
\hline Maule 01 & - & - & - & $\begin{array}{l}\text { Nothofagus dombeyi } \\
\text { (Mirbel) Oerst }\end{array}$ & - & 4,28 & 0,69 \\
\hline Lleu Lleu 01 & 220273 & $140+/-50$ & Cal. 1.660 a 1.950 DC & $\begin{array}{l}\text { Laurelia sempervirens } \\
\text { (R. et P.) Tul }\end{array}$ & - & 5,93 & 0,71 \\
\hline Lanalhue 01 & - & - & - & $\begin{array}{l}\text { Laurelia sempervirens } \\
\text { (R. et P.) Tul }\end{array}$ & - & 4,85 & 0,77 \\
\hline Pucura 1 & 205208 & $130+/-70$ & Cal. 1.650 a post $1.960 \mathrm{DC}$ & $\begin{array}{l}\text { Laurelia sempervirens } \\
\quad \text { (R. et P.) Tul }\end{array}$ & 46 & 6,20 & 0,95 \\
\hline Pucura 1 & 205209 & $330+/-80$ & $\begin{array}{l}\text { Cal. } 1.430 \text { a } 1.680 \mathrm{DC} \\
\text { Cal. } 1.770 \text { a } 1.800 \mathrm{DC} \\
\text { Cal. } 1.940 \text { a } 1.950 \mathrm{DC}\end{array}$ & $\begin{array}{l}\text { Laurelia sempervirens } \\
\text { (R. et P.) Tul }\end{array}$ & 174 & 5,84 & 0,66 \\
\hline
\end{tabular}

Lothrop (1932: 233 - 235) ha propuesto la única tipología tentativa de embarcaciones monóxilas de origen prehispánico para la zona Centro - Sur y Austral de Chile, compuesta por dos categorías: "monóxilas con proas aguzadas y popas cuadradas" y "canoas monóxilas con extremos aguzados", a base de evidencias etnohistóricas y etnográficas. Los ejemplares de canoas monóxilas documentadas arqueológicamente para la zona Centro - Sur han sido clasificadas de acuerdo a estas categorías (Carabias et al. 2007a; Lira 2007), siendo la canoa de la Laguna La Flor 01, próxima al lago Caburga, y con un fechado ${ }^{14} \mathrm{C}$ convencional de $270 \pm 50 \mathrm{AP}$ (Beta 220272) la única asignable a la categoría de "extremos aguzados" (Lira 2007: 198). Todos los casos de estudio señalados pueden ser atribuidos, de acuerdo al esquema de McGrail (1985), a la Clase $\mathrm{C} 1$, botes monóxilos simples, exclusivamente construidos mediante técnicas de reducción o sustracción de material (Carabias et al. 2007a; Lira 2007).

Con respecto a las dimensiones, es posible señalar que, salvo un caso excepcional -la canoa de Maullín 01 que alcanza sobre $7 \mathrm{~m}$ de eslora- estas embarcaciones exhiben dimensiones similares, variando su longitud entre aproximadamente 4 y 6 $\mathrm{m}$, y su ancho entre 0,7 y $1 \mathrm{~m}$. No obstante, estas diferencias de proporción en entre largo y ancho, las diferencias de tallado entre bordas convexas o paredes rectas en forma de "V" y el espesor del casco determinan formas, y por ende, comportamientos hidrodinámicos sustancialmente distintos dentro del universo de estudio.

Además de los hallazgos registrados en el centro-sur de Chile, existen antecedentes de casos en la vertiente oriental andina, en los territorios de Neuquén y Río Negro. A fines de la década de los setenta en el lago Nahuelhuapi, Provincia de Río Negro, Argentina, en Playa Bonita fue recuperada una canoa monóxila de 4,70 m de eslora, 0,85 m de puntal y 0,83 m de manga (Fernández 1978: 46). Habría sido fabricada en coigüe (Nothofagus dombeyii), presenta evidencias de quema y huellas de tallado con herramientas de metal. Una vez en seco, se le aplicaron análisis microxilográficos y aunque se pretendió obtener un fechado radiocarbónico, la fecha resultó incoherente. A pesar de haber sido realizada sin una metodología científica que permitiera la recuperación de la información contextual, esta iniciativa representa el primer referente de investigación de estas tecnologías de transporte de sistemas lacustres cordilleranos. Los hallazgos aislados en los lagos Nahuelhuapi, Lacar y Escondido elevarían a 15 el número de embarcaciones monóxilas en la vertiente oriental de la cordillera de Los Andes 
(Fernández 1978: 49-50; 1997: 51). En los últimos años, Braicovich (2004) realizó una sistematización y síntesis de la información sobre los hallazgos canoas registrados en la zona del Nahuelhuapi.

\section{OTRAS EVIDENCIAS}

Las evidencias más tempranas del conocimiento de prácticas de navegación en las costas del litoral higromórfico son indirectas y corresponderían a la ocupación de las islas Santa María y Quiriquina próximas a las costas de Arauco durante el Arcaico Medio, hacia el 4.500 AP (Seguel 1970; Quiroz 1997; Quiroz y Sánchez 2004). Con posterioridad, poblaciones pescadoras cazadoras recolectoras de alta movilidad y con dominio de técnicas de navegación ocupan esporádicamente la isla Mocha hacia el 3.300 AP (Vásquez 1994, 1997). Por otra parte, investigaciones arqueológicas en las regiones continentales de La Araucanía, Los Ríos y los Lagos han coincidido en señalar las evidencias de navegación detectadas en sitios arcaicos de la costa tanto por la presencia de ciertas especies de aguas profundas como por instrumental especializado (Navarro y Pino 1995, 1999; Navarro 2004; Gaete et al. 2004; Seguel 1970).

El análisis bioantropológico de colecciones correspondientes al período Alfarero en la isla Mocha, desde el Temprano hasta el Tardío, refuerza la idea de prácticas de navegación recurrentes con fines de movilidad y pesca. Constantinescu (1997: 171 188) ha identificado un conjunto de patologías que se pueden asociar a la acción de remar usando el remo como paleta en individuos de sexo femenino y masculino y, de edades fluctuantes entre los 25 y los 45 años. Todo lo anterior se refuerza con la presencia de instrumental de pesca como anzuelos y pesas de redes durante este período. Las prácticas de navegación entre las poblaciones del período Alfarero temprano se reflejan indirectamente en el arribo tardío a la isla Mocha - hacia el 900 DC - del Complejo Pitrén. Ya a mediados del siglo XVI, son poblaciones lafkenches pertenecientes al Complejo El Vergel quienes toman contacto con los europeos en las islas Santa María y Mocha (Aldunate 2005: 331 - 334).

Cabe señalar que para el período Alfarero Tardío se ha planteado la coexistencia de distintas prácticas de funebria, entre las cuales se registrarían los entierros en canoas funerarias o wampo ( $C f r$. Gordon 1978). Los enterratorios en canoas de troncos ahuecados, que aparecen en el Complejo El Vergel, adquieren gran popularidad durante el período poshispánico (Aldunate 1989: 342). Los ataúdes en troncos labrados no corresponden estrictamente a embarcaciones, pero a veces se ha tendido a establecer una cierta equivalencia formal derivada probablemente de que el término wampo, de origen quechua, sirve para designar cualquier tronco de árbol ahuecado, independientemente que se trate de una embarcación, una batea para hacer chicha, un ataúd o una acequia (Lenz 1895 - 1897 : 322). A esta identificación contribuyó poderosamente quizás Ricardo Latcham, quien interpretó los féretros como canoas con los que los "araucanos" cruzaban los ríos y su utilización funeraria como parte de una ofrenda simbólica para su uso en la otra vida (Latcham 1915: 59).

Para la zona cordillerana occidental no se han detectado indicadores concluyentes de prácticas de navegación para tiempos prehispánicos. En contraste, en la vertiente oriental de Los Andes, la presencia en la isla Victoria, la mayor del lago Nahuelhuapi, de yacimientos con arte rupestre y del sitio arqueológico Puerto Tranquilo 1 datado en su ocupación precerámica inicial en $1.980 \pm 60 \mathrm{AP}$, permiten suponer tempranamente el uso de embarcaciones (Hajduk 1991).

\section{DISCUSIÓN}

A partir de las múltiples evidencias arqueológicas, etnohistóricas y etnográficas presentadas queda de manifiesto que, por lo menos ya en el período Alfarero Tardío, el uso de embarcaciones en la extensa red de sistemas fluviales y lacustres que fluyen desde la cordillera al mar entre la cuenca del Bío-Bío y el Seno de Reloncaví, incluyendo probablemente la sección cordillerana de lagos Araucanos, era una práctica extendida y frecuente entre los grupos indígenas locales. Ahora bien, en este punto resulta legítimo interrogarse cuál es la profundidad temporal de estas prácticas, cuál fue su importancia relativa y por qué se volvieron social y culturalmente relevantes para los grupos Alfareros ¿y quizás también Arcaicos? ¿Existen implicancias teóricas relevantes subyacentes al uso de embarcaciones por parte de grupos con economías de caza y 
recolección? Si es así, ¿es posible distinguir a partir del registro arqueológico cazadores recolectores "acuáticos" de otros eminentemente pedestres?

Como ya se ha señalado, en forma teórica los cursos y cuerpos de agua del área de estudio han sido considerados elementos biogeográficos de importancia que habrían influido en ámbitos como la movilidad, la circulación de materiales y la organización de los sistemas de asentamiento (Cfr. Adán y Mera 1997; Aldunate 1989; Bengoa 2003; Dillehay 1990; García y Mera 2007). Los ríos y lagos representan elementos notables del paisaje físico que constituyen marcadores naturales, accidentes que pudieron constituir barreras que dificultaron el desplazamiento o bien, corredores para facilitar el movimiento. Cualquiera que sea el caso, desde la perspectiva de los mapas cognitivos, estos hitos del terreno contribuyen a las capacidades de "orientación" de los seres humanos, determinantes para los viajes en lugares a gran escala o macroambientes (Golledge 2003).

En forma indirecta se sabe que ya hacia el período Arcaico Medio, a los 4.500 AP, estaban disponibles en la costa del litoral higromórfico tecnologías de transporte que permitían la explotación de los ambientes insulares de La Araucanía (Vásquez 1994, 1997; Quiroz y Sánchez 2004). No se dispone de información concluyente sobre cuándo el uso de embarcaciones se desarrolla en la sección cordillerana del área de estudio. Las evidencias directas representadas por ejemplares de canoas monóxilas descubiertos en forma fortuita en lagos y ríos, aunque en algunos casos podrían ser prehispánicos, han arrojado fechas tardías. Los fechados radiocarbónicos de ejemplares ubicados en el eje meridional propuesto por Aldunate (1989) como la Canoa $N^{\circ} 2$ del sitio Dos Canoas y la canoa de Laguna La Flor 01, podrían estar documentado arqueológicamente estas tecnologías para momentos Alfarero Tardíos, que se caracteriza en la zona por una persistencia del Complejo Pitrén. Aunque tampoco se cuenta con evidencias directas controladas mediante fechados radiocarbónicos, en el ambiente cordillerano de bosques norpatagónicos del lago Nahuelhuapi cazadores recolectores habrían empleado embarcaciones al menos desde el 2.000 AP (Hajduk 1991).

Como queda expuesto, el abordar la problemática de las prácticas de navegación interior en la zona centro-sur a partir del registro arqueológico resulta una labor extremadamente compleja considerando el actual estado del arte en esta línea de investigación. Sólo en los últimos años se han abordado arqueológicamente los hallazgos fortuitos de embarcaciones indígenas (Carabias et al. 2007b; Lira 2007). Se cuenta con un número de fechados radiocarbónicos que no supera la decena y existen prácticamente nulas posibilidades de realizar fechados mediante dendrocronología ya que no existen secuencias maestras para las especies forestales involucradas, menos longevas. En otros casos, las canoas han sido sometidas a tratamientos de conservación mediante químicos que afectarían potenciales fechados. La incorporación de técnicas de arqueología subacuática ha posibilitado el estudio de restos arqueológicos en su contexto (Carabias et al. 2005, 2007a, 2010), pero las posibilidades de sistematizar la búsqueda de este tipo de yacimientos resultan bajas.

Otro problema relevante lo constituye la falta de investigación sobre el instrumental tecnológico necesario para la construcción y reparación de embarcaciones. Efectivamente, a pesar de la reconocida importancia del trabajo de los recursos del bosque templado por parte de poblaciones prehispánicas del centro-sur de Chile, prácticamente no se han realizado esfuerzos para correlacionar a partir del registro arqueológico el conjunto ergológico empleado para su explotación. Una reciente excepción destacable en ese sentido se refiere al desarrollo de una línea de arqueología experimental sobre micro huellas de uso en artefactos líticos a partir del trabajo de maderas locales y su comparación con el material de los sitios Marifilo 1 y Los Resfalines 1 (Cordero 2008).

Con todo, probablemente uno de los principales problemas radique en los modelos teóricos empleados. Efectivamente, según lo resume Fernández (1978: 56) para la zona cordillerana del Nahuelhuapi, la condición de navegantes no se condice con grupos prehistóricos / protohistóricos a los cuales clásicamente se les ha asignado un rol cultural de cazadores-recolectores. Recientes trabajos que abordan las posibilidades de interacción entre las vertientes oriental y occidental durante el Holoceno Tardío desde una perspectiva biogeográfica aunque no descartan el uso de embarcaciones por parte de cazadores-recolectores terrestres, estiman difícil evaluarlo ante la falta de evidencias directas tempranas 
(Belleli et al. 2008). El uso de canoas se identifica fuertemente al estereotipo de grupos "canoeros" que ocupan los ambientes marítimos del la vertiente Pacífico del centro-sur y Patagonia en Chile. Esta visión clásica no es ciertamente adecuada cuando se trata de grupos cazadores - recolectores de alta movilidad que explotan recursos con una marcada estacionalidad, pudiendo alternar fácilmente los desplazamientos terrestres con traslados por agua en los ambientes lacustres de la cordillera andina, como asimismo para poblaciones agrícolas o de economías mixtas, para las cuales la movilidad de recursos y personas es fundamental a su sistema social, tal como describieron extensamente los primeros conquistadores peninsulares.

Empleando las categorías de análisis de Kelly (1995), Ames (2002) realiza un análisis de los botes y su integración como instrumentos de producción y busca determinar si existen implicancias teóricas determinantes para el uso de embarcaciones por parte de grupos cazadores - recolectores. Este autor concluye que la utilización de embarcaciones puede incrementar las áreas de forrajeo y permitir largas incursiones logísticas, pero no necesariamente siempre es así. Las áreas de forrajeo e incursiones pueden ser del mismo tamaño para cazadores - recolectores acuáticos y terrestres. Sin duda, los cazadores - recolectores acuáticos que explotan los humedales y lagos del interior pueden no ser capaces de realizar viajes logísticos extensos. En función de lo anterior, sugiere que la importancia de las embarcaciones radica en el considerable mayor volumen y peso que pueden transportar en comparación con las personas a pie. Otra implicancia, menos obvia quizás, es que las embarcaciones pueden facilitar la explotación de pequeñas áreas de forrajeo permitiendo múltiples viajes en áreas reducidas y el despliegue de mayores grupos de tareas (Ames 2002: 37-39).

Ames propone un modelo para el paisaje del predador acuático donde sostiene que el grueso de las actividades de procesamiento probablemente se concentrarán poderosamente en el sitio residencial. La recolección se realiza en otros sectores, pero los recursos sin procesar (alimentos, materias primas líticas, etc.) son transportados al campamento base y procesados (o descartados) ahí, en vez de en el campo. Es más, a través del empleo de embarcaciones más recursos, así como recursos sin procesar más voluminosos pueden ser transportados al sitio residencial para ser procesados (Ames 2002: 37-39). Este patrón es predecible para los recursos marinos, pero podría extenderse a cualquier recurso accesible mediante embarcaciones. Lo anterior no excluye la existencia de campamentos especializados de tareas. Dichos sitios existen, no obstante, la implicancia planteada apunta a que los campamentos de tareas especializadas estarían inmersos en un paisaje arqueológico diferente de aquél previsto por los modelos clásicos de grupos recolectores (Ames 2002: 37-39).

Tomando como referencia la Tradición Arqueológica de Bosques Templados, el uso de embarcaciones puede haber resultado particularmente eficiente para actividades como las prácticas de captura de aves de hábitos lacustres mediante trampas (Velásquez y Adán 2004) y la recolección de moluscos dulceacuícolas. Otro aspecto hasta ahora no discutido que cabe destacar es la relevancia que tendría el transporte acuático para la recolección de plantas y frutos (Ames 2002: 39-42), lo que resulta particularmente si se considera el alto valor alimenticio de los frutos de la araucaria o pewen. No obstante, quizás las implicancias más determinantes de la incorporación de tecnologías de transporte para los cursos y cuerpos interiores de agua se relacionen con la movilidad y circulación de materiales (sensu García y Mera 2007). Dadas las características de los lagos Araucanos (Thomasson 1963) y su origen glaciar y considerando, en particular, la formas elongadas y la extensión de mucho de ellos, los desplazamientos acuáticos ofrecen importantes ventajas y mayor eficiencia en el plano de la movilidad y los desplazamientos en el espacio (Lira 2008-2009: 56).

A nivel de la zona centro-sur, las principales cuencas ofrecen importantes posibilidades biogeográficas, tanto para los desplazamientos terrestres siguiendo "corredores" a lo largo de los recursos hídricos como vías acuáticas o cursos navegables. En particular, el extenso y complejo sistema que drena desde Los Andes al océano Pacífico las hoyas hidrográficas donde se concentran los lagos preandinos de mayor extensión, se adapta particularmente bien al concepto de "redes", un conjunto integrado de "rutas" que se desarrollan para formalizar conexiones entre múltiples lugares en el ambiente. Tanto las "rutas" como las "redes" hacen los ambientes "legibles", en el sentido de organizar y facilitar los desplazamientos en el espacio (Golledge 2003: 38-39). 
El potencial de la navegación fluvial para embarcaciones menores como las canoas indígenas en estos "ríos tranquilos con regulación lacustre" se revela en su utilización en tiempos históricos republicanos por parte de embarcaciones de cabotaje, alcanzándose incluso hasta los cursos medios en el valle central (Cfr. Bengoa 2003). En varios casos, las condiciones hidrográficas incluso posibilitan la navegación en embarcaciones menores desde las cuencas lacustres ubicadas en el contacto entre el macizo andino y la depresión intermedia hasta su desembocadura al mar, sin mayores dificultades, posibilitando el recorrido de distancias superiores a $100 \mathrm{~km}$. La cuenca del río Toltén, que tiene su origen en el lago Villarrica y posee una longitud de $\sim 123 \mathrm{~km}$, es descendida en verano hasta su desembocadura en botes a remo por pescadores sin dificultades notables en tres días de navegación no forzada. Lo anterior destaca que las potencialidades de movilidad y circulación de materiales este - oeste vía fluvial son considerables y no deben ser desestimadas. Evidentemente, la construcción y utilización de canoas, rutas empleadas, duración de los viajes, cargas transportadas, emplazamiento de campamentos, puntos de desembarcos y asentamientos son todos elementos que forman parte de una adaptación eficiente y requieren de conocimiento altamente especializado (Wheeler et al. 2003: 547).

Con excepción de las cuencas más septentrionales del área como las del Bío - Bío, Imperial y Toltén de régimen mixto (nivopluvial), el régimen de alimentación de los ríos del área es de carácter exclusivamente pluvial, por lo que los incrementos de caudal se producen durante los meses de invierno, pudiendo dificultar o impedir su utilización como vías de tránsito. Pero los desplazamientos pueden ser realizados estacionalmente vía pedestre o usando embarcaciones, según sea más apropiado, o combinando rutas terrestres y acuáticas. Efectivamente, cuando las principales rutas acuáticas y sus alternativas no resultan navegables durante temporadas adversas pueden ser estratégicamente reemplazadas por rutas terrestres que se mantengan paralelas lo más posible a los cursos de agua (Nieves y Stoffle 2003: 63). Cox (1863: 132 - 133) refiere el uso de una ruta mixta alternativa empleada por parte de indios de Valdivia comerciando en el lago Lacar, en la vertiente oriental andina, cuando fueron sorprendidos por las nieves del invierno en el paso Huahum: a caballo hasta el lago Pirihueico, en canoa por el río Calletué (Choshuenco) hasta el lago Riñihue, completando un periplo de más de $12 \mathrm{~km}$ por tierra y $60 \mathrm{~km}$ por agua. Investigaciones etnográficas en el área del eje Villarrica - Lanín también coinciden en destacar la articulación de rutas de desplazamiento que combinan tramos terrestres y acuáticos entre ambas vertientes de la cordillera de Los Andes (Godoy 2009).

Adicionalmente, se ha sugerido que quizás la principal importancia de las embarcaciones radica en el considerable mayor volumen y peso que pueden transportar en comparación con las personas a pie (Ames 2002: 37-39). La observación anterior resulta relevante porque es posible que las embarcaciones monóxilas en la zona centro-sur, al igual que regiones de Norteamérica con extensos sistemas hídricos como Florida, sólo se hayan vuelto frecuentes cuando se transformaron en una herramienta integral para la recolección y el transporte de alimento (Kandare 1983 en Wheeler et al. 2003: 546). En ese sentido, la navegación como práctica cultural podría ser interpretada como un mecanismo de integración social; los cuerpos de agua ofrecen posibilidades importantes para el intercambio material y de alianzas entre grupos humanos, favoreciendo el aglutinamiento en torno a las cuencas de los lagos precordilleranos. Justamente, las poblaciones de los bordes de los lagos precordilleranos se beneficiaban de un intenso y productivo tráfico e intercambio con etnias serranas y pampeanas en tiempos de contacto (Aldunate 1989: 346).

Los botes monóxilos con frecuencia son considerados de estatus inferior, funcional y tecnológicamente (Nymoen 2008: 7 - 10). En el centro-sur de Chile han sido caracterizados como un recurso adaptativo no especializado, marcadamente multifuncional, siendo utilizado indistintamente para la navegación en ambientes marítimos, fluviales, palustres y lacustres de la amplia área comprendida entre el río Bío-Bío y el Seno del Reloncaví, y su distribución coincide con el territorio tradicional de poblaciones mapuche-williches (Carabias et al. 2007a: 503). En tiempos históricos tardíos, las canoas monóxilas fueron adoptadas por grupos canoeros fuego-patagónicos en proceso de desintegración cultural, como los kawésqar de isla Wellington y yámana de isla Navarino, reemplazando las embarcaciones de tablones o dalcas y de cortezas 
(Fernández 1978: 57, 60). Evidentemente, estas expresiones responden a otras tradiciones distintas a la del bosque templado del centro-sur, exhibiendo aspectos morfofuncionales, selección de maderas, y elementos constructivos distintivos, como por ejemplo, el ensanchamiento del casco mediante la aplicación de cuñas, aspecto no documentado en las canoas monóxilas analizadas del área de estudio y que probablemente se relacione con la disponibilidad de troncos de grandes dimensiones en estos ambientes.

Lira (2008-2009: 41-43), estima que las embarcaciones indígenas, y en forma particular las canoas monóxilas, podrían representar una manifestación material de la tecnología especializada en el uso de la madera. Aunque aún no existe información sólida y concluyente que permita suponer el uso de estas tecnologías de transporte específicas ya en el período Arcaico, sí coincidimos en que estas poblaciones cazadoras recolectoras de la costa y la precordillera de la zona centro-sur poseen un acumulación de experiencias y conocimientos avanzados sobre los recursos del bosque templado.

Con toda probabilidad, el conocimiento sobre los recursos forestales incluye un intensivo manejo del fuego. La técnica de reducción del tronco mediante combustión controlada documentada etnohistóricamente ha podido ser verificada arqueológicamente en el caso de varias canoas estudiadas. Siguiendo los planteamientos de Arnold (1995) en su estudio de embarcaciones monóxilas en Europa Central, se ha propuesto que además de su función de técnica de reducción durante la etapa de manufactura, este procedimiento podría ser aplicado para incrementar la resistencia de la madera al ataque de hongos e insectos, aumentando la vida útil de las embarcaciones (Lira 2007: 195 196). Lo anterior es relevante si se considera que algunas de los ejemplares que exhiben superficies carbonizadas también muestran huellas de herramientas metálicas, que permiten suponer que la aplicación de fuego para la reducción del tronco no habría sido necesaria. Hartmann (1996: 185 - 187) destaca que el contacto con los europeos no introdujo mayores cambios en las embarcaciones monóxilas de la región Sudeste de EEUU, lo que se explicaría debido a que estos transportes se adaptaban eficientemente a las condiciones medioambientales. No obstante, en las canoas de postcontacto se abandona la técnica de reducción mediante combustión controlada, lo que se atribuye a la incorporación de herramientas metálicas que aumentan la velocidad y eficiencia del proceso de fabricación de las canoas.

\section{CONCLUSIONES}

Resulta importante destacar la necesidad de analizar los casos de hallazgos fortuitos de embarcaciones en los contextos de los sistemas hídricos donde fueron identificados (Nymoen 2008). Las canoas monóxilas estudiadas, a pesar de diferencias morfológicas, anatómicas y constructivas sensibles, comparten una serie de rasgos que permiten asignarlas a una tradición y reflejan una tecnología conservadora eficientemente adaptada a los requerimientos de la navegación en ambientes fluviales y lacustres de la zona centro-sur. Aunque algunos ejemplares estudiados exhiben un casco de espesor reducido, lo que puede ser considerado un indicador de la necesidad de trasladar la embarcación de un cuerpo de agua a otro (Arnold 1995), no se han registrado antecedentes etnohistóricos ni etnográficos de prácticas de porteo por tierra de monóxilas, lo que permite proponer una navegación localizada o restringida a sistemas hídricos continuos interconectados o a cuerpos de agua localizados, que se distingue de las técnicas de navegación y porteo empleadas por los grupos "canoeros" marítimos del Pacífico.

Aunque la navegación en los lagos se presenta a simple vista como algo relativamente sencillo, existen factores a considerar. En primer lugar, se debe tener en cuenta que la densidad del agua es muchísimo menor que en el mar, por lo que los diversos materiales con los que se manufacturan las embarcaciones tienen una menor flotabilidad en este medio en comparación con el medio marítimo. Por otro lado, los vientos son menos constantes que en el medio marítimo, más impredecibles y sorpresivos. Estos vientos son capaces de producir fuertes oleajes, pudiendo en pocos minutos arreciar tan violentamente que impidan cualquier travesía (Lira 2008-2009: 56-57). Aunque probablemente destinadas a funciones múltiples y diferentes, las canoas monóxilas estudiadas debían responder en forma confiable y segura frente condiciones hidrodinámicas exigentes, como las que caracterizan el área de estudio. 
Adicionalmente, la identificación del laurel como la madera seleccionada para la fabricación de monóxilas procedentes tanto de ambientes lacustres costeros y cordilleranos del área de estudio da cuenta de un patrón de selección cultural; el uso de ésta y otras especies como el raulí (Nothofagus alpina) y el ulmo (Eucryphia cordifolia) refuerzan la hipótesis de que para la manufactura de embarcaciones monóxilas indígenas se han privilegiado maderas con propiedades que las hacen fáciles de trabajar, con una resistencia mecánica mediana y sin mayores complejidades en su secado (Lira 2007: 193).

De esta manera, y considerando la información proporcionada por las fuentes escritas, la tradición oral y las evidencias del registro material, se sugiere que las canoas monóxilas representan, al mismo tiempo, una tecnología de transporte de larga tradición y un elemento conservador en la cultura material de las poblaciones de la zona centro-sur. En particular, dada la larga ocupación humana verificada en los ambientes boscosos lacustres subandinos del sector meridional y las múltiples posibilidades que la navegación de los extensas cuencas lacustres y sus cursos de agua asociados ofrece en términos de movilidad, pero sobre todo, para la interacción social, y el intercambio material, se estima que la fabricación y uso de canoas constituiría un aspecto central de las formas de ocupar y habitar estos paisajes en la interfase de los lagos Araucanos y Los Andes. Sin perjuicio de lo anterior, en la costa y en el valle evidentemente también se desarrollaron prácticas similares.

Aunque se concluye que no existen antecedentes suficientes para determinar con exactitud en qué momento de la historia ocupacional del área se masificaron las tecnologías de transporte por agua, se estima que de acuerdo a las evidencias arqueológicas directas proporcionadas por algunas canoas monóxilas del eje meridional, ya se podría hablar con propiedad de su uso extendido hacia el Alfarero Tardío, siendo muy cautos en efecto. Con probabilidad, en el futuro se registren nuevos hallazgos que permitan profundizar temporalmente estas prácticas. En cualquier caso, la revisión de los modelos teóricos sobre cazadores recolectores sobre los cuales se desarrolla la investigación representaría un significativo avance ampliando las nociones clásicas que hemos manejado para el estudio de estas poblaciones.

\section{AGRADECIMIENTOS}

El presente trabajo ha sido desarrollado en el marco del proyecto de investigación FONDECYT 1060216. Agradecemos a Carla Morales, Renato Simonetti y Valentina Figueroa por su colaboración con las imágenes.

\section{BIBLIOGRAFÍA}

ADAN, L. Y R. MERA. 1997. Acerca de la distribución espacial y temporal del Complejo Pitrén. Una reevaluación a partir del estudio sistemático de colecciones. Boletín de la Sociedad Chilena de Arqueología 24: 33-37. Santiago.

ADÁN, L., C. GARCÍA Y R. MERA. 2010. La Tradición Arqueológica de Bosques Templados y su estudio en la región lacustre cordillerana de las regiones IX y XIV (centro-sur de Chile). En Actas del XVII Congreso Nacional de Arqueología Chilena, Tomo 2, 1461-1471, Valdivia, Ediciones Kultrún.

ADAN, L., C. GARCÍA, R. MERA, M. GODOY y D. CARABIAS. 2005. Habitando bosques, lagos y volcanes: comparación de las ocupaciones Arcaico y Alfarero Temprano en los ámbitos cordilleranos Llaima-Lonquimay y Villarrica-Lanin (39오). Postulación Concurso Nacional de Proyectos FONDECYT 2006. [MS]

ADÁN, L., V. REYES Y R. MERA. 2004. Ocupación humana de los Bosques Templados del centro-sur de Chile. Proposiciones acerca de un modo de vida tradicional. En IV Congreso Chileno de Antropología, Tomo II: 1144-1155. Santiago.

AMES, K.M. 2002. Going by Boat: The Forager-Collector Continuum at Sea. En Beyond Foraging and Collecting: Evolutionary Change in Hunter-Gatherer Settlement Systems, B. Fitzhugh y J. Habu (eds.), Kluwer Academic/ Plenum Publishers, New York. Pp.19-52.

ALDUNATE, C. 1989. Estadio alfarero en el sur de Chile. En Culturas de Chile. Prehistoria, J. Hidalgo, V. Schiapacasse, H. Niemeyer, C. Aldunate e I. Solimano (eds.). Editorial Andrés Bello, Santiago. Pp. 329-348.

ALDUNATE. C. 2005. Una reevaluación del Complejo Cultural El Vergel. En Actas del XVI Congreso Nacional de Arqueología Chilena. Museo Nacional de Historia Natural de Concepción, Dirección de Bibliotecas, Archivos y Museos y Sociedad Chilena de Arqueología. Escaparate Ediciones, Concepción. Pp. 331 - 336.

ARMESTO, J., P. LEÓN-LOBOS y M. KALIN. 1996. Los bosques templados del sur de Chile y Argentina: una 
isla biogeográfica. Ecología de los Bosques Nativos de Chile. Editado por Armesto, Villagrán y Kalin . Editorial Universitaria, Santiago.

ARNOLD, B. 1995. Pirogues monoxyles d' Europe Centrale: construction, typologie, evolution. Archéologie Neuchâteloise 20 - 21, Neuchâtel. Dos volúmenes.

BAHAMONDEZ, M. y P. VALENZUELA. 2001. Conservación del patrimonio sumergido: un nuevo desafío en Chile. En Actas de las Primeras Jornadas Latinoamericanas de Arqueología Subacuática. Ediciones de la Universidad Internacional SEK, Santiago. Pp. 109 - 115.

BELLELLI, C. V. SCHEINSOHN y M.M. PODESTÁ. 2008. Arqueología de pasos cordilleranos: un caso de estudio en Patagonia Norte durante el Holoceno Tardío. Boletín del Museo Chileno de Arte Precolombino, Vol. $N^{\circ} 13$ (2): 37 - 55. Santiago.

BENGOA, J. 2003. Historia de los antiguos mapuches del Sur. Desde antes de la llegada de los españoles hasta las paces de Quilín. Editorial Catalonia, Santiago.

BRAICOVICH, R. 2004. Las canoas del Parque Nacional Nahuel Huapi. Tesis presentada para optar al grado de Licenciado en Antropología, Escuela de Antropología de la Facultad de Humanidades y Artes de la Universidad Nacional de Rosario, Argentina.

BUSTAMANTE, A., F. DE LA MAZA, G. GONZÁlEZ, L. LUNA, G. SILVA y T. VEINTIE. 2005. La comunidad Mapuche de Putue cuenta su historia. Comité de Desarrollo Agrícola de Putue, Comunidad Indígena Pedro Ancalef, Equipo de Investigadores Pontificia Universidad Católica de Chile Sede Villarrica. Villarrica.

CARABIAS, D., M. CHAPANOFF y L. ADÁN. 2005. Evaluación Arqueológica Subacuática del Sitio "Dos canoas del lago Calafquén, Comuna de Panguipulli, Región de Los Lagos. Proyecto FONDECYT 1040326. Informe de Avance Año 1. [MS.]

CARABIAS, D., M. CHAPANOFF y L. ADÁN. 2007a. Evidencias de navegación en ambientes lacustres precordilleranos andinos: evaluación arqueológica subacuática del sitio "Dos Canoas del lago Calafquén". En Arqueología de Fuego-Patagonia. Levantando piedras, desenterrando huesos... y develando arcanos, F. Morello, M. Martinic, A. Prieto y G. Bahamonde (eds.). Ediciones CEQUA, Punta Arenas. Pp. 503 - 514.

CARABIAS, D., N. LIRA y M. CHAPANOFF. $2007 \mathrm{~b}$. Documentación, análisis e interpretación de los restos de una dalca procedentes del lago Chapo, Región de los Lagos. En Arqueología de Fuego - Patagonia. Levantando piedras, desenterrando huesos... y develando arcanos, F.Morello, M. Martinic, A. Prieto y G.
Bahamonde (eds.). Ediciones CEQUA, Punta Arenas. Pp. $257-267$

CARABIAS, D., R. SIMONETTI y C. MORALES. 2010. Reconocimientos arqueológicos subacuáticos en los lagos Villarrica y Calafquén, Regiones de la Araucanía - Los Lagos. Proyecto FONDECYT 1060216. Informe final. [MS].

CONSTANTINESCU, F. 1997. Reconstruir un antiguo modo de vida: un nuevo desafío desde la bioantropología. En La Isla de las palabras Rotas. Biblioteca Nacional de Chile, Centro de Investigación Diego Barros Arana. Pp. 169-193.

COOPER, J. 1946. Handbook of South American Indians. Volume 2: The Andean Civilizations, J. Steward (ed.). Bulletin 143. Smithsonian Institution, Bureau of American Ethnology, Washington D.C. Pp. 687 - 760.

CORDERO, R. 2008. Tras la huella de los cazadores recolectores de la Tradición de Bosques Templados. Memoria de titulo para obtener el título profesional de Arqueólogo. Departamento de Antropología, Facultad de Ciencias Sociales, Universidad de Chile, Santiago.

COX, G. 1863. Viaje en las Regiones Septentrionales de la Patagonia, 1862 - 1863. Imprenta Nacional, Santiago

DEWEESE, B.L. 2007. Oral traditions and the archaeological record of a Wabanaki maritime society. Master of Arts dissertation, Department of Anthropology, Florida State University.

DÍAZ MEZA, A. 1907. En la Araucanía: Breve Relación del Último Parlamento Araucano de $\mathrm{Coz}-\mathrm{Coz}, 18$ de Febrero de 1907. Colecciones Memoria Indígena. Ser Indígena Ediciones.

DONOSO, C. 1993. Bosques Templados de Chile y Argentina. Variación, estructura y dinámica. Editorial Universitaria, Santiago, Chile.

DILLEHAY, T.D. 1990. Araucanía. Presente y Pasado. Editorial Andrés Bello, Santiago.

EDWARDS, C. 1965. Aboriginal watercraft on the Pacific Coast of South America. Ibero-Americana, 47. University of California Press. Berkeley and Los Angeles.

FERNÁNDEZ, J. 1978. Restos de embarcaciones primitivas en el lago Nahuelhuapi. Anales de Parques Nacionales, Tomo XIV. Buenos Aires. Pp. 45 - 77.

FERNÁNDEZ, J. 1997. Canoas arqueológicas de un palo (huampus) recuperadas en los lagos andinos del Noroeste Patagónico. Anuario de la Universidad Internacional SEK, 3/1997. Ediciones de la Universidad Internacional SEK. Santiago. Pp. 49-63.

FONCK, F. 1900. Viajes de fray Francisco Menéndez a Nahuelhuapi. Ed. F. Niemeyer, Valparaíso. Dos tomos. 
GAETE, N., X. NAVARRO, F. CONSTANTINESCU, R. MERA, D. SELLES, M. SOLARI, L. VARGAS, D. OLIVA y L. DURAN. 2004. Una mirada al modo de vida canoero del mar interior desde Piedra Azul. Chungará Revista de Antropología Chilena volumen especial, Tomo I: 333-346.

GAJARDO, R. 1994. La vegetación natural de Chile. Clasificación y distribución geográfica. Editorial Universitaria, Santiago.

GARCÍA, C. y R. MERA. 2007. Investigación de rutas de circulación y movilidad de cazadores recolectores en la cuenca del río Valdivia a través del tiempo. En Arqueología de Fuego-Patagonia. Levantando piedras, desenterrando huesos... y develando arcanos, F.Morello, M. Martinic, A. Prieto y G. Bahamonde (eds.). Ediciones CEQUA, Punta Arenas. Pp. 515 - 525.

GARDEWEG, M., H. MORENO Y J.A. NARANJO. 1990. Comportamiento del volcán Lonquimay en su fase eruptiva 1988-1990 y su influencia en el medio ambiente. Informe Inédito, Biblioteca Servicio Nacional de Geología y Minería,

GODOY, M. 2005 [MS]. Informe Etnográfico Proyecto Fondecyt № 1040326 Año 1. Cuenca del Río Valdivia, Sector Cordillera, Comuna de Panguipulli.

GODOY, M. 2009. Territorio y Movilidad en la Araucanía Andina: el caso del Eje Villarrica - Lanín. [MS.]

GODOY, M. y N. LIRA. 2007. Etnoarqueología para la comprensión de las canoas del lago Calafquén, Panguipulli, Región de Los Ríos, Chile. Ponencia presentada en el VI Congreso Nacional de Antropología, Valdivia. [MS]

GOLLEDGE, R.G. 2003. Human wayfinding and cognitive maps. En Colonization of unfamiliar landscapes: the archaeology of adaptation, M. Rockman y J. Steele (eds.). Routledge, New York. Pp. 25 - 43.

GÓNGORA Y MARMOLEJO, A. 1862 [1536-1575]. Historia de Chile. Desde su descubrimiento Hasta el Año 1575. Colección de Historiadores de Chile, Tomo II. Imprenta del Ferrocarril, Santiago.

GONZÁLEZ DE AGÜEROS, P. 1791. Descripcion Historial de la Provincia y Archipielago de Chiloe en el Reyno de Chile, y Obispado de la Concepcion. Imprenta de don Benito Cano, Madrid.

GORDON, A. 1978. Urna y canoa funeraria. Una sepultura doble excavada en Padre Las Casas. Prov. de Cautín, IX Región, Chile. Revista Chilena de Antopología 1. Santiago. Pp. 61-80.

GUARDA, G. 1994. Una ciudad chilena del siglo XVI. Valdivia 1552-1604. Urbanística. Res Pública. Economía. Sociedad. Ediciones Universidad Católica de Chile. Santiago.
GÜELL, S. 1982. Noticia breve y moderna del archipiélago de Chiloé, de su terreno, costumbres de los indios, misiones, escrita por un misionero de aquellas islas en el año 1769 y 70. En La Isla de Chiloé. Capitana de Rutas Australes, Hanisch W. Academia Superior de Ciencias Pedagógicas de Santiago, Santiago. Pp. 220 - 263.

GUERRERO, V. 2006. Comer antes que viajar. Pesca y barcas de base monóxila en la prehistoria occidental. Mayurqa, 31: 7 - 56. http://www.raco.cat/index.php/Mayurqa/ article/viewFile/122770/170001

HAJDUK, A. 1991. Sitio arqueológico de contacto hispanoindígena Llao- Llao. Comunicaciones científicas del Museo de la Patagonia Francisco Pascasio Moreno 2(2): 1-24, Buenos Aires.

HARTMANN, M.J. 1996. The Development of Watercraft in the Prehistoric Southeastern United States. Ph.D. dissertation, Department of Anthropology, Texas A\&M University.

JULIET, C. 1874. Informe del ayudante de la comision exploradora de Chiloé i Llanquihue. En Anuario hidrográfico de la Marina de Chile, Tomo 1. Pp. 265 - 338.

KELLY, R. 1995. The Foraging Spectrum: Diversity in HunterGatherer Lifeways. Smithsonian Institution Press, Washington D.C.

LATCHAM, R. 1915. Costumbres mortuorias de los indios de Chile y otras partes de América. Sociedad Imprenta y Litografía Barcelona. Santiago, Valparaíso.

LENZ, R. 1897. Estudios Araucanos Materiales para el Estudio de la Lengua, la Literatura i las Costumbres de los Indios. En Anales de la Universidad de Chile, Tomo XCVII. Imprenta Cervantes, Santiago. Pp. 1 - 447.

LIRA, N. 2007. Canoas monóxilas en el centro-sur de Chile: navegando sobre los árboles. Memoria de titulo para obtener el título profesional de Arqueólogo. Departamento de Antropología, Facultad de Ciencias Sociales, Universidad de Chile, Santiago.

LIRA, N. 2008-2009. Embarcations de tradition indigène dans la Patagonie du Nord. Connexions, contacts et routes entre le versant oriental et occidental des Andes. Mémoire de Master 2 Préhistoire- Ethnologie- Anthropologie. Université de Paris I Panthéon- Sorbonne, U.F.R d'art et d'archéologie.

LIRA, N. 2010. Canoas Monóxilas en el centro-sur de Chile: Navegando sobre los árboles. Actas del XVII Congreso Nacional de Arqueología Chilena, Tomo 2, 1473-1485, Valdivia, Ediciones Kultrún.

LOTHROP, S.K. 1932. Aboriginal Navigation off the West Coast of South America. The Journal of the Royal Anthropological Institute of Great Britain And Ireland, Vol. 62. Pp. $229-256$. 
MARIÑO DE LOBERA, P. 1865. Crónica del Reino de Chile. Colección de Historiadores de Chile, Tomo IV. Imprenta del Ferrocarril, Santiago.

McGRAIL, S. 1985. Towards a classification of water transport. World Archaeology, Vol. 16., No. 3 Water Craft and Water Transport. Pp. 289 - 303.

MEDINA, J.T. 1928. Relación del viaje de Hendrick Brouwer en 1643. Imprenta Universitaria, Santiago.

MERCER, J.H. 1972. Chilean glacial chronology 20.000 to $11.000{ }^{14}$ Carbon years ago: some global comparisons. Science 76:1118-1120.

MORENO, H. 1990. Excursión al Truful Truful. Guía geológica. Corporación Nacional Forestal (CONAF). Temuco, Chile.

MURÚA, R. 1995. Comunidades de mamíferos del bosque templado de Chile. En Ecología de los bosques nativos de Chile, J. Armesto, C. Villagrán y M. K. Arroyo (eds.). Editorial Universitaria, Santiago. Pp. 113-133

NAVARRO, X. 2004. Paisajes arqueológicos y territorialidad en la zona Centro Sur de Chile. Recuento actualizado de la historia prehispánica del área ubicada entre Tirúa y Valdivia. Cultura, Hombre y Sociedad 8: 71-86.

NAVARRO, X. y M. PINO. 1995. Interpretación de ocupaciones precerámicas y cerámicas en los distintos microambientes de la costa de Chan Chan, Valdivia, X Región. En Actas del XIII Congreso Nacional de Arqueología Chilena. Hombre \& Desierto, Antofagasta, 9 (1): 127 - 134.

NAVARRO, X. y M. PINO. 1999. Ocupaciones arcaicas en la costa de Valdivia. El sitio Chan-Chan-18. En Actas de las III Jornadas de Arqueología de la Patagonia, pp. 65-82. Bariloche.

NIEVES, M. y R.W. STOFFLE. 2003. Tracking the role of pathways in the evolution of a human landscape: the St. Croix Riverway in ethnohistorical perspective. En Colonization of unfamiliar landscapes: the archaeology of adaptation, M. Rockman y J. Steele (eds.). Routledge, New York. Pp. 59 - 80.

NYMOEN, P. 2008. Boats for rivers and mountains: sources for new narratives about river travel? The International Journal of nautical Archaeology 37 (1): 3 - 16.

OCAMPO, C. y P. RIVAS. 2004. Nuevos datos sobre el poblamiento temprano de los extremos geográficos de los canales patagónicos. Isla de Chiloé e Isla Navarino. En Actas del XV Congreso Chileno de Arqueología. Universidad de Tarapacá, Sociedad Chilena de Arqueología. Arica.

PHILIPPI, F. 1865. Excursión botánica en Valdivia desde los Cuncos en el departamento de la Unión, a través de la Cordillera de la Costa, hasta la mar. En Anales de la Universidad de Chile, XXVII (3): 289-351. Imprenta Nacional, Santiago.
QUIROZ, D. 1997. Fragmentos recuperados: un breve panorama histórico para la Isla Mocha. En La Isla de las Palabras Rotas, compilado por D. Quiroz y M. Sánchez, pp. 237-241. Ediciones de la Biblioteca Nacional de Chile. Centro de Investigaciones Diego Barros Arana. Santiago.

QUIROZ, D. y SANCHEZ, M. 2004. Poblamientos iniciales en la costa septentrional de La Araucanía (6.500-2.000 AP.). Chungará, Arica. Vol.36, suppl., Tomo I. Pp. 289-302.

RIFFO, P. 1984. Volcanes dormidos del lago Caburgua. Boletín del Museo Regional de la Araucanía 1:13-23.

RIVAS, P. y C. OCAMPO. 2010. La adaptación humana al bosque en la Isla de Chiloé. Estrategias adaptativas en el litoral septentrional de los canales patagónicos. En Actas del XVII Congreso Nacional de Arqueología Chilena, tomo 2, 1449-1460, Valdivia, Ediciones Kultrún.

RIVAS, P., C. OCAMPO, y E. ASPILLAGA. 1999. Poblamiento temprano de los canales Patagónicos: el núcelo ecotonal septentrional. Anales del Instituto de la Patagonia, serie CS, volumen 27, Punta Arenas.

ROSALES, D. 1877 - 1878 [1678]. Historia general del reyno de Chile, Flandes Indiano. Tomos I y II. Publicada anotada y precedida por B. Vicuña Mackenna. Imprenta de El Mercurio, Valparaíso.

SEGUEL, Z. 1970. Investigaciones Arqueológicas en la Isla Quiriquina. Rehue 3: 39-47. Concepción.

SEÑORET, M. 1878. Exploración del río Bueno y lago Ranco. En Anuario Hidrográfico de la Marina de Chile, Tomo IV. Pp. $25-63$.

SOTO, D. y H. CAMPOS. 1996. Los lagos oligotróficos del bosque templado húmedo del sur de Chile. En Ecología de los Bosques Nativos de Chile, J. Armesto, C. Villagrán y M. Kalin (eds.). Editorial Universitaria, Santiago. Pp. 317-334.

STEWARD, J. y L. FARON. 1959. Native Peoples of South America. McGraw-Hill, New York.

SUBIABRE, A. y C. ROJAS. 1994. Geografía Física de la Región de Los Lagos. Ediciones Universidad Austral de Chile. Dirección de Investigación y Desarrollo, Valdivia.

THOMASSON, K. 1963. Araucarian lakes. Acta Phytogeographica Sve. 47: 1-139

TREUTLER, P. 1861. La Provincia de Valdivia y los Araucanos. Imprenta Chilena, Santiago.

TREUTLER, P. 1958. Andanzas de un alemán en Chile: 1851 - 1863. Editorial del Pacífico. Santiago.

VÁSQUEZ, M. 1994. Navegantes y pescadores de la costa sur chilena. Museos, 19: 24-28.

VÁSQUEZ, M. 1997. El Arcaico en la Isla Mocha. En La Isla de las palabras Rotas. Biblioteca Nacional de Chile, Centro de Investigación Diego Barros Arana. Pp. 215-235. 
VELÁSQUEZ, H. y L. ADÁN. 2004. Marifilo-1: evidencias arqueofaunísticas para entender las relaciones hombre y bosques templados en los sistemas lacustres cordilleranos del centro-sur de Chile. En Contra viento y marea. Arqueología de Patagonia, M.T. Civalero, P.M. Fernández y A.G. Guraieb (eds.). Instituto Nacional de Antropología y Pensamiento Latinoamericano, Buenos Aires. Pp. 507 - 519.

VIDAL GORMAZ, F. 1867. Exploración Hidrográfica de la Costa y ríos de la Araucanía. Imprenta Nacional, Santiago.
VIDAL GORMAZ, F. 1879. Instrucciones sobre el Puerto de Corral y Río Valdivia. En Anuario Hidrográfico de la Marina de Chile, Tomo V. Pp. 167 - 172.

VIVAR, G. DE. 1966 [1558]. Cronica y relacion copiosa y verdadera de los reynos de Chile. Fondo Histórico y Bibliográfico José Toribio Medina y The Newberry Library Chicago. Santiago.

WHEELER, R.J., J.J. MILLER, R.M. McGEE, D. RUHL, B. SWANN y M. MEMORY. 2003. Archaic Period canoes from Newnans Lake, Florida. American Antiquity, 68 (3): $533-551$. 